\title{
28. MAGNETIC PETROLOGY OF BASALTS FROM NINETYEAST RIDGE ${ }^{1}$
}

\author{
Guy M. Smith, ${ }^{2}$ Jeff Gee, ${ }^{3}$ and Christian T. Klootwijk ${ }^{4}$
}

\begin{abstract}
Given the importance of the inversion of seamount magnetic anomalies, particularly to the motion of the Pacific plate, it is important to gain a better understanding of the nature of the magnetic source of these features. Although different in detail, Ninetyeast Ridge is composed of submarine and subaerial igneous rocks that are similar to those found at many seamounts, making it a suitable proxy. We report here on the magnetic petrology of a collection of samples from Ninetyeast Ridge in the Indian Ocean. Our purpose is to determine the relationship between primary petrology, subsequent alteration, and magnetic properties of the recovered rocks. Such information will eventually lead to a more complete understanding of the magnetization of seamounts and presumably improvements in the accuracy of anomaly inversions. Three basement sites were drilled on Ninetyeast Ridge, with recovery of subaerial basalt flows at the first two (Sites 756 and 757) and submarine massive and pillow flows at the final one (Site 758). The three sites were distinctly different. Site 756 was dominated by ilmenite. What titanomagnetite was present had undergone deuteric alteration and secondary hematite was present in many samples. The magnetization was moderate and stable although it yielded a paleolatitude somewhat lower than expected. Site 757 was highly oxidized, presumably while above sea level. It was dominated by primary titanomagnetite, which was deuterically altered. Secondary hematite was common. Magnetization was relatively weak but quite stable. The paleolatitude for all but the lowermost flows was approximately $40^{\circ}$ lower than expected. Site 758 was also dominated by primary titanomagnetite. There was relatively little oxidation with most primary titanomagnetite showing no evidence of high-temperature alteration. No secondary hematite was in evidence. This site had the highest magnetization of the three (although somewhat low relative to other seamounts) but was relatively unstable with significant viscous remanence in many samples. Paleolatitude was close to the expected value. It is not possible, at present, to confidently associate these rocks with specific locations in a seamount structure. A possible and highly speculative model would place rocks similar to Site 757 near the top of the edifice, Site 756 lower down but still erupted above sea level, and Site 758 underlying these units, erupted while the seamount was still below sea level.
\end{abstract}

\section{INTRODUCTION}

Although marine magnetic anomaly work has focused primarily on the linear anomalies produced by spreading at ridges, the magnetization of seamounts has received attention as far back as the early sixties (e.g., Vacquier, 1962; Talwani, 1965). A major reason for this interest has been the use of the inversion of magnetic anomalies associated with seamounts to generate paleomagnetic poles. This technique is particularly valuable in the Pacific, where conventional paleomagnetic sampling is severely limited (e.g., Francheteau et al., 1970; Harrison et al., 1975; Gordon and Cox, 1980; Hildebrand and Parker, 1987). As with all such inversions, the source cannot be uniquely determined, leading to uncertainty in the derived paleopole. Knowledge of the magnetic structure of seamounts should help evaluate the validity of such inversions and possibly permit more reliable determinations of seamount paleopoles.

While attempts have been made to acquire information about the source by sophisticated inversion techniques (e.g., Harrison, 1971; Sager et al., 1982; Parker et al., 1987) a substantial degree of nonuniqueness is unavoidable. Direct information about the magnetization of seamounts can only be obtained by the study of samples of seamount lithologies potentially capable of contributing to a magnetic anomaly. The most straightforward approach is to simply measure the parameters relevant to modeling (susceptibility and remanent magnetization primarily) and assume that

\footnotetext{
${ }^{1}$ Weissel, J., Peirce, J., Taylor, E., Alt, J., et al., 1991. Proc. ODP, Sci. Results, 121: College Station, TX (Ocean Drilling Program).

${ }^{2}$ Department of Earth and Atmospheric Sciences, St. Louis University, St. Louis, MO 63103, U.S.A.

${ }_{3}^{3}$ Scripps Institution of Oceanography, La Jolla, CA 92093, U.S.A.

${ }^{4}$ Bureau of Mineral Resources, Geology and Geophysics, P.O. Box 386, Canberra ACT 2601, Australia.
}

these can be applied to an arbitrary seamount. The shortcoming of this approach is that seamounts have a fair amount of variability in their petrology and alteration history, so that information from one seamount, or even some sort of averaged properties, may not be applicable to the seamount of interest. What we are attempting to do here is not only to measure the basic magnetic parameters necessary for modeling but also to understand their relationship to the primary petrology and subsequent alteration. Given the petrology and alteration history of a seamount, we may eventually be able predict its magnetic properties with much better accuracy than is presently possible.

A better understanding of seamount magnetization may also improve our understanding of the more general problem of seafloor magnetization. Mid-ocean ridge basalts are generally thought to have a fairly monotonous magnetic mineralogy (e.g., Johnson, 1979). Seamounts allow us to study a broader range of compositions and emplacement settings, as well as different types of post-emplacement chemical alteration. We can thus improve our understanding of seafloor magnetization by placing it in a much broader context.

There has been a modest amount of work done previously on the magnetic properties of seamount basalts. The three basic approaches to sampling have been dredging (e.g., Merrill and Burns, 1972; Furuta et al., 1980; Gee et al., 1988), drilling (Marshall, 1978; Rice et al., 1980; Kono, 1980), and studying subaerially exposed sections on oceanic islands (Gee et al., 1989). In general, these studies have shown that seamount magnetic properties not only differ from those found in "typical" seafloor basalts but are highly variable both within and among seamounts. While this work has given us some information about seamount magnetization, clearly more is needed. Dredging, while relatively easy, only samples the surface of the seamount, and provides no insight into the possible contributions of the intrusive and buried extrusive units found in the interior of the edifice. Although generally 
restricted to relatively young rocks, exposed seamounts can provide excellent study sections, even of gabbros. However, the rocks studied have remained above sea level and may have undergone different postemplacement alteration, yielding different magnetic properties. Drilling, at least in principle, allows in-situ sampling of any seamount, including the submerged ones that are of primary interest. It is not restricted to the surface but may go deep into the edifice-current Ocean Drilling Program (ODP) capability is perhaps $2 \mathrm{~km}$ sub-basement. Although the coverage is sparse and sampling is virtually random, such studies are the ground truth that must ultimately be examined. Drilling to date has been relatively limited, with only shallow penetration of the subaerial sections of a small number of seamounts (Marshall, 1978; Rice et al., 1980; Kono, 1980). What is needed is sufficiently deep penetration of seamounts to sample intrusive and deeply buried extrusive rocks that may form a significant part of the anomaly source (Gee et al., 1989). Whereas the sites drilled on Ninetyeast Ridge do not exceed $200 \mathrm{~m}$ and leave many questions unanswered, they still add significantly to our limited understanding of even the shallow subsurface of these structures.

\section{GEOLOGIC SETTING}

Ninetyeast Ridge is an aseismic, linear bathymetric high running roughly along $90^{\circ} \mathrm{E}$ longitude from approximately $30^{\circ} \mathrm{S}$ latitude, immediately northwest of Broken Ridge, to about $10^{\circ} \mathrm{N}$ latitude, where it disappears under the Bengal Fan (Fig. 1). It is the trace of the Kerguelen-Heard hot spot, resulting from the northward motion of the Indian plate. Morphologically, the ridge has some similarities to the Hawaiian-Emperor seamount chain, although the eruptive activity has produced a ridge of coalescent volcanic centers rather than a chain of discrete islands. Whereas Ninetyeast Ridge is clearly not a seamount in the strict sense, study of its magnetization is still valuable. Although the overall morphology is different, Ninetyeast Ridge's magma composition, style and depth of emplacement, and subsequent thermal and chemical evolution are similar to that of many more typical seamounts.

The latter half of ODP Leg 121 sampled the basement of Ninetyeast Ridge at Sites 756, 757, and 758 at its southern, central, and northern extreme sections, respectively (Fig. 1). Hotspot reconstruction gives ages of 49 (Site 756), 58 (Site 757), and 80 m.y. (Site 758) (Duncan, 1978; Duncan et al., in press). Argon $39 / 40$ dating gives basement isochron ages of $43.3 \pm 1.5$ and 42.1 $\pm 0.7 \mathrm{~m}$.y. (Site 756), 59.1 (total fusion) and $57.9 \pm 1.6 \mathrm{~m} . \mathrm{y}$. (Site 757 ), and $71.3 \pm 7.6$ and $83.4 \pm 2.4 \mathrm{~m} . \mathrm{y}$. (Site 758). Corresponding plateau ages are $42.0 \pm 0.6$ and $44.5 \pm 0.7$ m.y. (Site 756), $55.6 \pm$ 0.4 m.y. (Site 757 , second sample only), and $80.7 \pm 3.5$ and 83.1 \pm 3.9 m.y. (Site 758) (R. A. Duncan, pers. comm., 1990). The following discussion of basement lithology is based on material from Peirce, Weissel, et al. (1989) and Frey et al. (this volume) unless otherwise indicated. The basement of Ninetyeast Ridge recovered on Leg 121 is composed largely of tholeiitic basalt. The exception is some of the youngest lavas from Site 756, which are transitional between tholeiitic and alkalic basalt. The trace element character is intermediate between oceanic island and midocean ridge basalts. Whereas ferrobasalts have been recovered from Ninetyeast Ridge at Deep Sea Drilling Project (DSDP) Sites 214 and 216 , the $\mathrm{FeO} / \mathrm{MgO}$ ratios of the sections sampled on Leg 121 were generally less than 2.0 , although two units from Site 756 exceeded this value.

Site 756 consists of massive flows that appear to have been deposited in a subaerial environment. Basement penetration was $82.0 \mathrm{~m}$ with a recovery of $33 \%$. The rocks are aphyric or sparsely plagioclase phyric and contain few vesicles. They are generally moderately altered, apparently under oxidizing conditions, as indicated by the generally tan color and the presence of hematite in some samples. Alteration minerals consist largely of clays and calcite. No zeolites were observed. Site 757 also consists of massive subaerial flows. Basement penetration was $48.3 \mathrm{~m}$ with a recovery of $52 \%$. The rocks are generally plagioclase phyric, some highly so (30\%). Most are vesicular (up to $25 \%$ in some units). Alteration ranges from slight to high with alteration minerals including clays, calcite, limonite, hematite, and zeolites. Alteration was generally oxidative, as most of the samples are dull red, presumably due to disseminated pigment hematite. A few are dark, however, suggesting locally reducing conditions. Site 758 was apparently deposited in deep water and consists of sheet and massive flows in the upper part of the section with four recognizable pillow units near the bottom of the hole (flow Units 758A-F19, $758 \mathrm{~A}-\mathrm{F} 21,758 \mathrm{~A}-\mathrm{F} 23$, and 758A-F25). Basement penetration was $177.9 \mathrm{~m}$ with a recovery rate of $70 \%$. The massive flow units are predominantly aphyric or sparsely plagioclase phyric. The proportion of mesostasis is quite high, reaching $70 \%$ in some units (now consisting largely of smectite). The sheet flow and pillow basalt units tend to be either aphyric or contain small amounts of olivine or clinopyroxene phenocrysts. The proportion of vesicles is as high as $20 \%$, but typically much less. Alteration is pervasive, ranging from moderate to high. Mesostasis is totally replaced by smectites, with rare calcite. Alteration generally appears to have occurred under reducing conditions, although there is some latestage oxidation associated with calcite veins.

\section{MAGNETIC MEASUREMENTS}

The mafic igneous rocks that make up seamounts are a far from homogeneous group, and their petrology is controlled by a large number of factors (e.g., Chen and Frey, 1983; Flower, 1973; Schmincke, 1976). As all of these factors can affect magnetic properties, simply measuring the parameters necessary for modeling purposes is of limited value because the results cannot necessarily be applied to other seamounts. In order for these measurements to be generally useful, it is necessary to understand how the primary basalt chemistry, mode of emplacement, and alteration history affect the magnetic mineralogy and how these parameters are related to the overall structure of the seamount. This paper focuses primarily on the relationship between petrological variables and magnetic mineralogy. Most of the conventional paleomagnetic measurements are discussed separately (Klootwijk et al., this volume).

The basic approach of the work discussed here is to characterize the samples from both a magnetic and mineralogical standpoint. Magnetic characterization includes the natural remanent magnetization (NRM), initial susceptibility $\left(\chi_{0}\right)$, alternating field (AF) demagnetization of NRM, and hysteresis loop analysis. The mineralogy is constrained by reflected-light microscopy and electron microprobe measurements of selected samples. Combined with the petrologic characterization (Frey et al., this volume), the measurements should give us some idea of how magnetic properties relate to various petrologic parameters. Further measurements, including Curie temperatures, will be presented in the open literature when available.

\section{NRM Measurements}

NRM is one of the principle parameters necessary for understanding seamount magnetization. In the limit that NRM is large compared to induced magnetization, the NRM is entirely responsible for the anomaly. NRM measurements include the NRM value itself as well as the demagnetization behavior of the magnetization vector. The values of NRM, median demagnetizing field $(\mathrm{MDF})$, initial inclination $\left(\mathrm{I}_{0}\right)$, and stable inclination $\left(\mathrm{I}_{\mathrm{S}}\right)$ are given in Table 1 for Sites 756 through 758 . They are also plotted with other measurements in Figures 2 through 4 . In order to fully evaluate the potential of these rocks as magnetic sources we also 


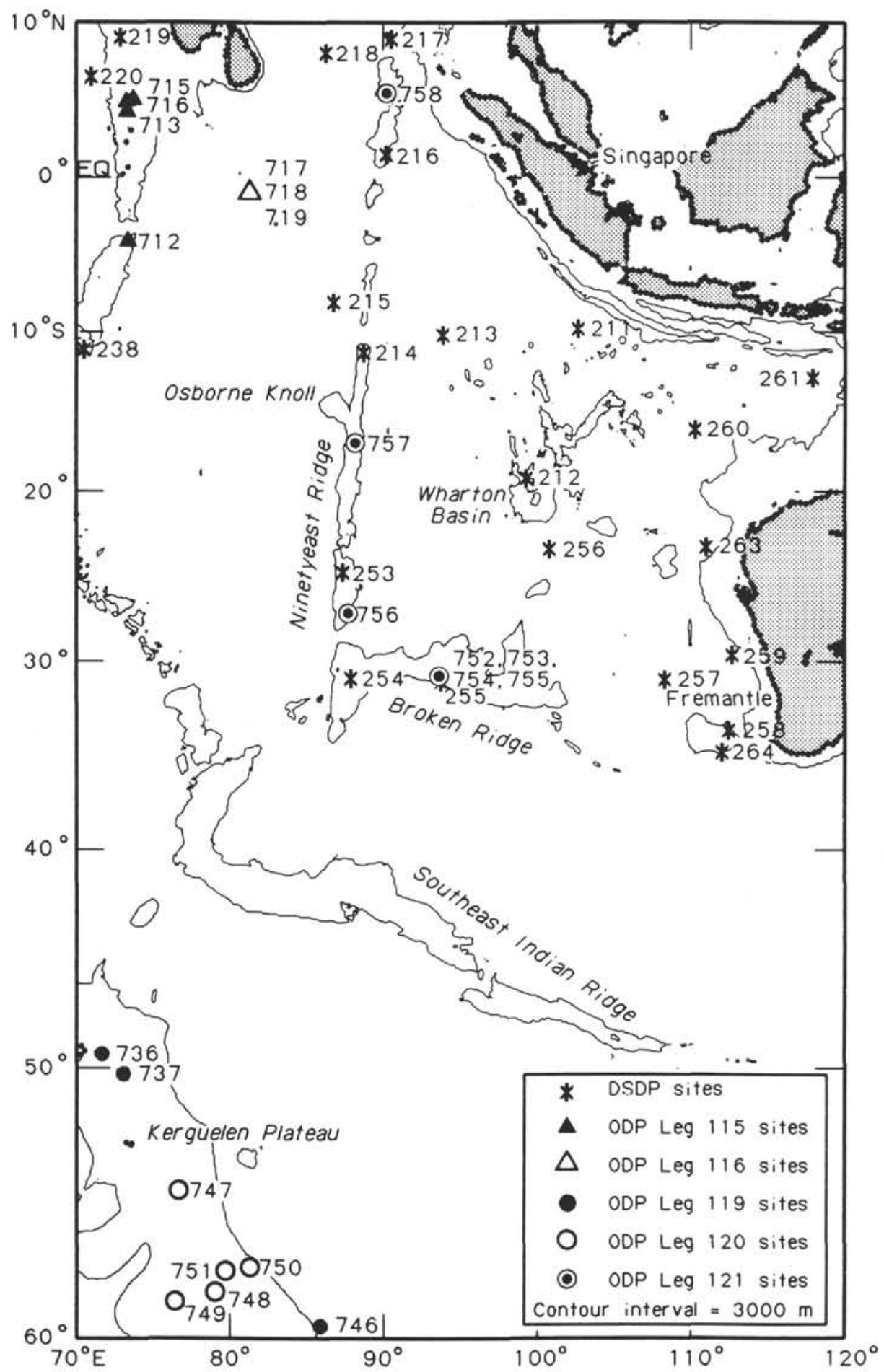

Figure 1. Site map of the eastern Indian Ocean showing the location of Ninetyeast Ridge and Sites 756, 757 , and 758 .

include $\chi_{0}$ and the Koenigsberger ratio (Q). The Koenigsberger ratio is the ratio of NRM to the magnetization induced by the Earth's field and gives a rough estimate of the relative contributions to an anomaly of remanent and induced magnetization. The exact value of $\mathrm{Q}$ depends on the choice of the field. This is commonly taken as the field at the site (as we will do here), but the values must be corrected for differences in the field for close comparison. For comparison, NRM, $\chi_{0}$, and $\mathrm{Q}$ values for several other seamounts are given in Table 2 .
NRM magnitudes for Site 756 range from 0.29 to $5.12 \mathrm{~A} / \mathrm{m}$ with the majority in the $1-2 \mathrm{~A} / \mathrm{m}$ range (arithmetic mean, 1.54 $\mathrm{A} / \mathrm{m}$; geometric mean, $1.18 \mathrm{~A} / \mathrm{m}$ ). Samples were stepwise demagnetized in an alternating field demagnetizer until less than $10 \%$ of the original remanence remained or the limit of the demagnetizer was reached $(150 \mathrm{mT})$. Vector demagnetization commonly shows a clearly defined primary magnetization with an average inclination of $61^{\circ}$ and an alpha 95 (as defined by the McFadden-Reid method; McFadden and Reid, 1982) of $3^{\circ}$. "Primary" magnetiza- 
Table 1. NRM and some optical and microprobe data from Sites 756, 757, and 758.

\begin{tabular}{|c|c|c|c|c|c|c|c|c|c|c|}
\hline $\begin{array}{l}\text { Core, section, } \\
\text { interval }(\mathrm{cm})\end{array}$ & $\begin{array}{l}\text { Depth } \\
\text { (mbsf) }\end{array}$ & $\begin{array}{l}\text { Flow } \\
\text { unit }\end{array}$ & $\begin{array}{c}\text { NRM } \\
\text { intensity } \\
(\mathrm{A} / \mathrm{m})\end{array}$ & $\begin{array}{c}\mathrm{I}_{0} \\
\text { (degrees) }\end{array}$ & $\begin{array}{c}\begin{array}{c}\mathrm{I}_{\mathrm{s}} \\
\text { (degrees) }\end{array}\end{array}$ & $\begin{array}{l}\text { MDF } \\
(\mathrm{mT})\end{array}$ & $\begin{array}{c}\text { Ex- } \\
\text { solution }\end{array}$ & $\begin{array}{l}\text { Low- } \\
\text { temperature } \\
\text { alteration }\end{array}$ & $x_{0}$ & Q \\
\hline \multicolumn{11}{|l|}{$121-756 \mathrm{D}-$} \\
\hline $4 R-1,47-49$ & 139.5 & F1 & $5.49 \mathrm{e}-1$ & 60 & (b) & 122 & Absent & Low & $1.04 \mathrm{e}-2$ & 1.3 \\
\hline $4 \mathrm{R}-1,90-92$ & 139.9 & F2 & $3.84 \mathrm{e}-1$ & 59 & (b) & 290 & Absent & Low & $1.70 \mathrm{e}-2$ & 0.6 \\
\hline $5 \mathrm{R}-1,25-27$ & 148.9 & F2 & 1.02 & -48 & 60 & 96 & Absent & Low & $8.65 e-3$ & 2.9 \\
\hline $5 \mathrm{R}-1,46-48$ & 149.1 & F2 & 1.08 & 75 & (b) & 730 & Present & Low & $1.05 \mathrm{e}-2$ & 2.5 \\
\hline${ }^{a_{10}}-1,27-29$ & 150.6 & F1 & $2.86 \mathrm{e}-1$ & (c) & (c) & (c) & Absent & Low & $6.30 \mathrm{e}-3$ & 1.1 \\
\hline${ }^{\mathrm{a}} 10 \mathrm{~N}-3,82-84$ & 154.1 & F1 & (a) & (a) & (a) & (a) & Absent & Medium & $7.00 e-3$ & (a) \\
\hline $6 \mathrm{R}-1,73-75$ & 159.0 & F5 & 1.52 & 55 & 58 & 736 & Present & Low & $5.81 \mathrm{e}-3$ & 6.4 \\
\hline $6 R-2,5-7$ & 159.9 & F5 & (a) & (a) & (a) & (a) & Present & Low & $5.64 e-3$ & 4.5 \\
\hline $7 \mathrm{R}-1,41-43$ & 168.4 & F6 & 1.52 & 33 & 64 & 1125 & Present & Low & $1.87 \mathrm{e}-2$ & 2.0 \\
\hline $7 R-1,104-106$ & 169.0 & F6 & 3.62 & -22 & (b) & 46 & Absent & Medium & $2.18 \mathrm{e}-2$ & 4.1 \\
\hline $7 \mathrm{R}-2,98-100$ & 170.5 & F6 & 1.45 & 42 & 63 & 948 & Present & Low & $9.04 e-3$ & 3.9 \\
\hline $7 \mathrm{R}-3,47-49$ & 171.4 & F6 & $7.03 e-1$ & 44 & (b) & 662 & Present & Medium & $8.44 \mathrm{e}-3$ & 2.04 \\
\hline $7 R-4,65-67$ & 173.0 & F6 & 5.26 & 54 & 60 & 478 & Present & Medium & $2.78 \mathrm{e}-2$ & 4.6 \\
\hline $9 \mathrm{R}-1,71-73$ & 188.1 & F9 & 1.86 & -64 & (b) & 284 & Present & Low & $8.52 e-3$ & 5.4 \\
\hline $9 \mathrm{R}-2,32-34$ & 189.0 & F9 & 1.34 & 53 & 58 & 934 & Present & Low & $3.88 \mathrm{e}-3$ & 8.5 \\
\hline $9 \mathrm{R}-3,67-69$ & 190.8 & F9 & 2.87 & 64 & 59 & 379 & Present & Low & $1.28 \mathrm{e}-2$ & 5.5 \\
\hline 10R-1, 94-96 & 197.9 & F12 & 1.09 & 47 & 61 & 1017 & Present & Low & $3.44 \mathrm{e}-3$ & 7.8 \\
\hline $10 \mathrm{R}-2,84-86$ & 199.3 & F12 & $8.49 \mathrm{e}-1$ & 71 & (b) & 378 & Present & Low & $2.58 \mathrm{e}-3$ & 8.1 \\
\hline $10 \mathrm{R}-3,46-48$ & 200.5 & F12 & 1.05 & 50 & 55 & 672 & Present & Low & $4.40 e-3$ & 5.9 \\
\hline $11 R-1,7-9$ & 206.7 & F13 & 1.89 & 67 & 67 & 1131 & Present & Low & $3.00 \mathrm{e}-3$ & 15.5 \\
\hline $11 \mathrm{R}-1,97-99$ & 207.6 & F13 & $9.46 \mathrm{e}-1$ & 65 & 62 & 712 & Absent & Low & $2.65 e-3$ & 8.7 \\
\hline $11 R-1,110-112$ & 207.7 & F13 & $6.48 \mathrm{e}-1$ & 63 & (b) & 1312 & Present & Low & $2.86 \mathrm{e}-3$ & 5.6 \\
\hline $11 R-2,84-86$ & 208.9 & F14 & 1.81 & -16 & 59 & 257 & Present & Low & $2.31 \mathrm{e}-2$ & 1.9 \\
\hline $12 \mathrm{R}-1,86-88$ & 217.1 & F14 & 1.19 & 76 & (b) & 421 & Present & Low & $8.12 e-3$ & 3.59 \\
\hline $12 \mathrm{R}-2,3-5$ & 217.4 & F14 & $9.44 \mathrm{e}-1$ & 57 & 63 & 905 & Present & Low & $6.24 \mathrm{e}-3$ & 3.7 \\
\hline $12 \mathrm{R}-2,92-94$ & 218.3 & F14 & 1.13 & 60 & (c) & (c) & Present & Medium & $6.25 e-3$ & 4.4 \\
\hline $12 R-3,25-27$ & 219.1 & F14 & (a) & (a) & (a) & (a) & Present & Low & 0.82 & (a) \\
\hline \multicolumn{11}{|l|}{$121-757 \mathrm{C}-$} \\
\hline $8 \mathrm{R}-1,69-71$ & 373.3 & F1 & $1.57 \mathrm{e}-1$ & 32 & 25 & 963 & Absent & Low & $2.57 e-3$ & 1.62 \\
\hline $8 R-1,122-124$ & 374.0 & F2 & $2.03 e-1$ & 19 & 25 & $>1500$ & Present & Low & $5.69 \mathrm{e}-3$ & 0.94 \\
\hline $8 R-2,61-63$ & 374.5 & $\mathrm{~F} 2$ & $1.38 \mathrm{e}-1$ & 16 & (b) & 409 & Absent & High & $5.01 \mathrm{e}-3$ & 0.73 \\
\hline $8 \mathrm{R}-2,89-91$ & 374.8 & F2 & $1.13 \mathrm{e}-1$ & 25 & 35 & 1000 & Present & Medium & $2.85 \mathrm{e}-3$ & 1.1 \\
\hline $9 \mathrm{R}-1,26-28$ & 382.3 & F2 & $3.78 \mathrm{e}-1$ & 16 & 27 & 468 & Present & Low & $5.39 \mathrm{e}-3$ & 1.9 \\
\hline $9 R-2,92-94$ & 384.1 & F2 & $2.62 \mathrm{e}-2$ & 8 & 5 & 87 & Present & Low & $4.68 \mathrm{e}-3$ & 1.5 \\
\hline $9 R-3,98-100$ & 385.1 & $\mathrm{~F} 2$ & 1.08 & 7 & 18 & 58 & Present & Low & $4.37 e-1$ & 1.2 \\
\hline $9 R-4,69-71$ & 386.1 & F3 & $3.71 \mathrm{e}-1$ & 37 & 30 & 283 & Present & Low & $6.83 \mathrm{e}-3$ & 0.42 \\
\hline $9 \mathrm{R}-4,86-88$ & 386.3 & F3 & $3.80 \mathrm{e}-1$ & 23 & (b) & 655 & Present & Low & $2.11 \mathrm{e}-3$ & 4.8 \\
\hline $9 \mathrm{R}-4,127-129$ & 386.7 & F4 & $3.71 \mathrm{e}-1$ & 37 & 30 & 283 & Present & Low & $3.26 \mathrm{e}-3$ & 3.0 \\
\hline 9R-5, 31-33 & 387.1 & F4 & $3.65 \mathrm{e}-1$ & 25 & 40 & 510 & Present & Low & $7.07 e-3$ & 1.4 \\
\hline $9 \mathrm{R}-6,20-22$ & 387.8 & F5 & $6.98 \mathrm{e}-1$ & 29 & 30 & 98 & Present & Low & $1.09 \mathrm{e}-2$ & 1.7 \\
\hline $9 R-6,66-68$ & 388.3 & F5 & $3.29 \mathrm{e}-1$ & 22 & 28 & 596 & Present & Low & $2.94 \mathrm{e}-3$ & 3.0 \\
\hline $9 \mathrm{R}-7,25-27$ & 389.0 & F5 & $9.98 \mathrm{e}-2$ & 11 & 20 & 610 & (a) & (a) & $4.10 \mathrm{e}-3$ & 0.64 \\
\hline $9 \mathrm{R}-7,136-138$ & 390.1 & F5 & $9.01 e-2$ & 49 & 36 & 297 & Present & Low & $4.74 \mathrm{e}-3$ & 0.50 \\
\hline $9 \mathrm{R}-8,71-73$ & 390.9 & F5 & $1.53 \mathrm{e}-1$ & 34 & 18 & 1200 & Present & Medium & $5.69 \mathrm{e}-3$ & 0.71 \\
\hline $10 \mathrm{R}-1,39-41$ & 392.1 & F6 & $2.55 e-1$ & 45 & 31 & 671 & Present & Low & $4.68 \mathrm{e}-3$ & 1.4 \\
\hline $10 \mathrm{R}-1,61-63$ & 392.3 & F6 & $4.27 \mathrm{e}-1$ & 10 & 17 & 47 & Present & Low & $6.56 \mathrm{e}-3$ & 1.7 \\
\hline $10 \mathrm{R}-2,20-22$ & 393.3 & F6 & $3.05 e-1$ & 16 & 14 & 251 & Absent & Low & $6.43 e-3$ & 1.3 \\
\hline $10 \mathrm{R}-2,70-72$ & 393.8 & F7 & $2.53 \mathrm{e}-1$ & -19 & (b) & 438 & Present & Low & $7.11 \mathrm{e}-3$ & 0.94 \\
\hline $10 R-3,7-9$ & 394.6 & F8 & $3.55 \mathrm{e}-1$ & -21 & -27 & 364 & Absent & Low & $9.60 \mathrm{e}-3$ & 1.0 \\
\hline 10R-3, 77-79 & 395.3 & F9 & $2.89 \mathrm{e}-1$ & 40 & (b) & 1017 & Absent & Low & $3.95 \mathrm{e}-3$ & 1.9 \\
\hline $11 \mathrm{R}-1,78-80$ & 402.2 & F10 & $6.30 e-1$ & 79 & 82 & NA & Present & Low & $6.61 e-3$ & 2.5 \\
\hline $11 \mathrm{R}-1,115-117$ & 402.6 & F11 & 1.70 & 82 & 75 & 235 & Present & Low & $9.39 \mathrm{e}-3$ & 4.8 \\
\hline $11 \mathrm{R}-2,49-51$ & 403.5 & $\mathrm{~F} 13$ & $4.99 \mathrm{e}-1$ & 71 & 80 & 448 & Present & Low & $1.82 \mathrm{e}-2$ & 0.73 \\
\hline $11 \mathrm{R}-2,100-102$ & 403.9 & F14 & $2.77 e-1$ & 84 & (b) & 1202 & Present & Low & $4.08 \mathrm{e}-3$ & 1.8 \\
\hline IIR-3, 47-49 & 404.7 & F16 & $8.23 \mathrm{e}-1$ & 78 & 65 & 337 & (c) & (c) & $6.68 \mathrm{e}-3$ & 3.3 \\
\hline $11 R-3,115-117$ & 405.4 & F17 & $4.86 e-1$ & -9 & (b) & 43 & Present & Low & $1.12 \mathrm{e}-2$ & 1.2 \\
\hline $12 \mathrm{R}-1,2-4$ & 411.1 & F18 & $2.06 \mathrm{e}-1$ & 54 & 65 & 251 & Present & Medium & $1.21 \mathrm{e}-2$ & 0.45 \\
\hline $12 \mathrm{R}-1,30-32$ & 411.4 & F18 & (a) & (a) & (a) & (a) & Absent & Low & (c) & (c) \\
\hline 12R-1, 53-55 & 411.6 & F18 & $3.71 \mathrm{e}-1$ & 61 & (b) & 260 & Absent & Low & $1.82 \mathrm{e}-2$ & 0.54 \\
\hline $12 \mathrm{R}-1,65-67$ & 411.8 & F18 & (a) & (a) & (a) & (a) & Absent & Low & (c) & (c) \\
\hline 12R-1, 117-119 & 412.3 & F18 & (a) & (a) & (a) & (a) & Absent & Low & (c) & (c) \\
\hline $12 \mathrm{R}-3,8-10$ & 413.7 & F19 & $6.82 \mathrm{e}-1$ & 63 & 80 & $>1500$ & Absent & Low & $6.05 e-3$ & 0.30 \\
\hline $12 \mathrm{R}-3,108-110$ & 414.7 & F19 & $9.45 \mathrm{e}-1$ & 85 & 82 & 540 & Absent & Low & $6.77 e-3$ & 3.7 \\
\hline $12 \mathrm{R}-3,127-129$ & 414.9 & F19 & $3.10 \mathrm{e}-1$ & 74 & 71 & 939 & Absent & Low & $7.51 \mathrm{e}-3$ & 1.09 \\
\hline $12 \mathrm{R}-3,132-134$ & 415.0 & F19 & $8.84 \mathrm{e}-1$ & 77 & 75 & 526 & Present & Low & $6.20 \mathrm{e}-3$ & 3.8 \\
\hline
\end{tabular}


Table 1 (continued).

\begin{tabular}{|c|c|c|c|c|c|c|c|c|c|c|}
\hline $\begin{array}{l}\text { Core, section, } \\
\text { interval }(\mathrm{cm})\end{array}$ & $\begin{array}{l}\text { Depth } \\
\text { (mbsf) }\end{array}$ & $\begin{array}{l}\text { Flow } \\
\text { unit }\end{array}$ & $\begin{array}{c}\text { NRM } \\
\text { intensity } \\
(\mathrm{A} / \mathrm{m})\end{array}$ & $\begin{array}{c}\mathrm{I}_{0} \\
\text { (degrees) }\end{array}$ & $\begin{array}{c}\mathrm{I}_{\mathrm{s}} \\
\text { (degrees) }\end{array}$ & $\begin{array}{l}\text { MDF } \\
(\mathrm{mT})\end{array}$ & $\begin{array}{c}\text { Ex- } \\
\text { solution }\end{array}$ & $\begin{array}{l}\text { Low- } \\
\text { temperature } \\
\text { alteration }\end{array}$ & $x_{0}$ & Q \\
\hline \multicolumn{11}{|l|}{$121-758 \mathrm{~A}-$} \\
\hline $55 R-1,94-96$ & 499.8 & F1 & 3.61 & -86 & -85 & 34 & $\begin{array}{l}\text { Cracking } \\
\text { Absent }\end{array}$ & High & $2.69 \mathrm{e}-2$ & 4.1 \\
\hline $55 \mathrm{R}-5,86-88$ & 505.4 & F1 & 1.74 & -37 & -37 & 40 & Absent & High & $3.18 \mathrm{e}-2$ & 1.7 \\
\hline $56 \mathrm{R}-1,69-71$ & 509.1 & F1 & 1.13 & -16 & -60 & 48 & Absent & Medium-high & $3.51 \mathrm{e}-2$ & 1.0 \\
\hline 56R-1, 113-117 & 509.5 & F1 & (a) & (a) & (a) & (a) & Absent & Absent & (a) & (a) \\
\hline $57 R-3,15-17$ & 520.8 & F2 & 4.36 & -35 & -55 & 92 & (a) & (a) & $4.89 \mathrm{e}-2$ & 2.8 \\
\hline $58 R-2,15-17$ & 528.7 & F2 & 2.76 & -44 & -65 & 130 & Present & (a) & $4.20 \mathrm{e}-2$ & 2.0 \\
\hline $58 R-2,44-46$ & 529.0 & $\mathrm{~F} 2$ & 3.29 & -52 & -53 & 119 & Present & (a) & $4.08 \mathrm{e}-2$ & 2.5 \\
\hline $58 \mathrm{R}-4,14-16$ & 531.7 & F2 & 4.24 & 88 & 68 & 34 & Absent & High & $4.00 \mathrm{e}-2$ & 3.3 \\
\hline 58R-6, 137-139 & 535.5 & F2 & 2.12 & -54 & -57 & 44 & (a) & Low-medium & $4.42 \mathrm{e}-2$ & 1.5 \\
\hline $59 \mathrm{R}-1,136-138$ & 537.9 & F2 & 3.54 & -18 & 100 & 34 & Absent & Medium & $4.06 \mathrm{e}-2$ & 2.7 \\
\hline 59R-2, 102-104 & 538.9 & F2 & 0.852 & -62 & (b) & 84 & Absent & Medium & $4.21 \mathrm{e}-2$ & 0.62 \\
\hline $59 \mathrm{R}-6,65-67$ & 544.1 & $\mathrm{~F} 2$ & 2.15 & -61 & -55 & 198 & Present & Medium-high & $3.82 \mathrm{e}-2$ & 1.7 \\
\hline $60 \mathrm{R}-1,74-75$ & 546.6 & $\mathrm{~F} 2$ & (a) & (a) & (a) & (a) & Present & (a) & (a) & (a) \\
\hline $60 \mathrm{R}-2,12-14$ & 547.3 & F3 & 8.15 & -69 & (b) & (a) & Present & (a) & $2.76 \mathrm{e}-2$ & 9.1 \\
\hline $60 \mathrm{R}-6,108-110$ & 553.8 & F3 & 1.28 & -13 & -63 & 190 & Absent & Medium & $5.74 \mathrm{e}-2$ & 0.69 \\
\hline $61 R-1,36-38$ & 555.5 & F3 & 1.58 & -31 & -62 & 43 & Absent & Medium & $3.60 \mathrm{e}-2$ & 1.3 \\
\hline $61 \mathrm{R}-7,12-14$ & 563.0 & F3 & 1.85 & -32 & 100 & 29 & Absent & Medium-high & $3.86 \mathrm{e}-2$ & 1.5 \\
\hline $61 R-7,11-13$ & 563.0 & F3 & (a) & (a) & (a) & (a) & Absent & Medium-high & (a) & (a) \\
\hline $62 \mathrm{R}-1,25-27$ & 564.6 & F3 & 4.07 & -77 & -65 & 43 & Absent & (a) & $4.14 \mathrm{e}-2$ & 3.0 \\
\hline $62 \mathrm{R}-2,125-127$ & 567.0 & F4 & 1.27 & -10 & 100 & 87 & Absent & Medium & $1.68 \mathrm{e}-2$ & 2.3 \\
\hline $63 R-2,114-116$ & 576.3 & F7 & 1.55 & -36 & -80 & 82 & Absent & Low-medium & $4.87 e-2$ & 1.0 \\
\hline $63 R-4,129-131$ & 579.1 & F7 & 2.12 & -33 & -67 & 115 & Present & Low-medium & $4.91 \mathrm{e}-2$ & 1.3 \\
\hline 63R-6, 133-135 & 581.9 & F7 & 1.19 & -36 & -54 & 79 & Absent & Medium & $4.02 \mathrm{e}-2$ & 0.91 \\
\hline $64 \mathrm{R}-1,123-125$ & 584.4 & F7 & 1.20 & -49 & -70 & 121 & Absent & Low-medium & $4.66 \mathrm{e}-2$ & 0.79 \\
\hline $64 \mathrm{R}-2,92-94$ & 585.4 & F7 & 2.15 & -44 & -69 & 91 & Absent & Medium & $4.06 \mathrm{e}-2$ & 1.6 \\
\hline $64 \mathrm{R}-2,109-111$ & 585.6 & F7 & (a) & (a) & (a) & (a) & Absent & Medium & (a) & (a) \\
\hline $64 \mathrm{R}-3,114-116$ & 587.1 & F9 & (a) & (a) & (a) & (a) & Absent & Medium-high & $3.90 \mathrm{e}-2$ & (a) \\
\hline $65 \mathrm{R}-1,38-40$ & 593.1 & F9 & (a) & (a) & (a) & (a) & Absent & (a) & (a) & (a) \\
\hline $65 \mathrm{R}-1,62-64$ & 593.3 & F10 & 1.46 & -56 & -67 & 82 & Absent & Absent & $3.83 e-2$ & 1.2 \\
\hline $65 \mathrm{R}-3,24-26$ & 595.5 & F10 & 2.12 & -56 & -71 & 45 & Absent & (a) & $4.73 \mathrm{e}-2$ & 1.4 \\
\hline $65 \mathrm{R}-5,96-98$ & 599.0 & F10 & $9.42 \mathrm{e}-1$ & -43 & -83 & 115 & Absent & Present & $3.50 \mathrm{e}-2$ & 0.83 \\
\hline $66 \mathrm{R}-2,110-112$ & 604.7 & F11 & 1.24 & -17 & -66 & 50 & Absent & High & $3.29 \mathrm{e}-2$ & 1.2 \\
\hline $66 \mathrm{R}-4,123-125$ & 607.4 & F11 & 2.04 & -60 & -76 & 120 & (a) & (a) & $4.11 \mathrm{e}-2$ & 1.5 \\
\hline $66 \mathrm{R}-6,55-57$ & 609.0 & F12 & 1.72 & -43 & -65 & 48 & (a) & (a) & $4.33 \mathrm{e}-2$ & 1.2 \\
\hline $67 \mathrm{R}-1,87-89$ & 612.4 & F12 & 1.69 & -55 & -51 & 58 & (a) & (a) & $3.54 \mathrm{e}-2$ & 1.5 \\
\hline $67 R-3,29-31$ & 614.7 & F14 & 1.21 & -39 & -67 & 145 & Absent & Low & $5.08 \mathrm{e}-2$ & 0.73 \\
\hline $67 \mathrm{R}-3,80-82$ & 615.3 & F14 & 1.58 & -29 & -63 & 144 & Absent & Absent & $4.24 e-2$ & 1.2 \\
\hline $67 \mathrm{R}-4,122-124$ & 617.2 & F15 & 1.79 & -38 & -63 & 93 & Absent & Low & $4.68 \mathrm{e}-2$ & 1.2 \\
\hline $67 R-5,37-39$ & 617.8 & F15 & 3.29 & -29 & -62 & 38 & Absent & Low & $3.87 \mathrm{e}-2$ & 2.6 \\
\hline $68 \mathrm{R}-2,123-125$ & 623.5 & F16 & 2.98 & -56 & -61 & 133 & Present & Medium & $6.91 \mathrm{e}-2$ & 1.3 \\
\hline $68 R-3,72-74$ & 624.5 & F17 & 1.71 & 9 & -45 & 126 & Absent & Low & $3.95 e-2$ & 1.3 \\
\hline $68 R-4,33-35$ & 625.4 & F17 & 1.83 & -43 & -62 & 103 & Absent & Low & $3.71 \mathrm{e}-2$ & 1.5 \\
\hline $69 \mathrm{R}-1,23-25$ & 630.4 & F17 & (a) & (a) & (a) & (a) & Absent & Low & (a) & (a) \\
\hline $69 \mathrm{R}-2,109-111$ & 632.6 & F17 & $7.02 \mathrm{e}-1$ & -68 & -65 & 50 & (a) & (a) & (a) & (a) \\
\hline $69 R-4,58-60$ & 634.8 & F17 & 2.87 & -55 & -62 & 202 & Present & High & $3.59 \mathrm{e}-2$ & 2.5 \\
\hline $69 \mathrm{R}-5,27-29$ & 635.9 & F17 & (a) & (a) & (a) & (a) & Absent & Low-medium & (a) & (a) \\
\hline $69 \mathrm{R}-5,115-117$ & 636.8 & F17 & (a) & (a) & (a) & (a) & Present & Medium & (a) & (a) \\
\hline $69 \mathrm{R}-6,17-19$ & 637.1 & F18 & 3.06 & -34 & -53 & 40 & Absent & (a) & $4.35 \mathrm{e}-2$ & 2.2 \\
\hline $70 \mathrm{R}-1,74-76$ & 640.1 & F18 & 1.80 & -23 & -49 & 80 & Absent & Medium & $3.56 \mathrm{e}-2$ & 1.6 \\
\hline $70 R-2,67-69$ & 641.6 & F19 & 2.49 & -54 & -53 & 178 & Absent & (a) & $3.30 \mathrm{e}-2$ & 2.3 \\
\hline $71 R-1,89-91$ & 649.5 & F20 & 2.22 & -21 & -31 & 70 & Absent & Low & $3.31 \mathrm{e}-2$ & 2.1 \\
\hline $71 \mathrm{R}-3,121-123$ & 652.8 & F23 & 6.02 & -65 & -63 & 111 & Absent & (a) & $3.77 e-2$ & 4.9 \\
\hline $72 \mathrm{R}-1,91-93$ & 658.9 & F24 & 2.39 & -56 & -55 & 91 & Absent & Low & $4.03 e-2$ & 1.8 \\
\hline $72 R-2,72-74$ & 660.1 & F24 & 2.34 & -16 & -57 & 86 & Absent & Low & $4.17 e-2$ & 1.7 \\
\hline $72 \mathrm{R}-3,12-14$ & 661.0 & F25 & 5.24 & -71 & -52 & 97 & Absent & (a) & $3.96 \mathrm{e}-2$ & 4.4 \\
\hline $72 \mathrm{R}-4,50-52$ & 662.8 & F25 & 3.17 & -48 & -65 & 83 & Absent & Low & $4.02 \mathrm{e}-2$ & 2.4 \\
\hline $72 R-4,132-134$ & 663.6 & F25 & (a) & (a) & (a) & (a) & Absent & (a) & (a) & (a) \\
\hline $73 \mathrm{R}-1,121-123$ & 668.8 & F27 & 166 & -53 & -60 & 78 & Absent & (a) & $4.05 e-2$ & 1.2 \\
\hline $73 R-3,102-104$ & 671.5 & F29 & 1.88 & -54 & -65 & 105 & Absent & (a) & $4.40 \mathrm{e}-2$ & 1.3 \\
\hline $73 R-3,123-125$ & 671.8 & F29 & 195 & -39 & -64 & 108 & Absent & (a) & $4.74 \mathrm{e}-2$ & 1.2 \\
\hline
\end{tabular}

Note: (a) indicates that the parameter was not determined for this sample, (b) indicates that no stable inclination could be determined, and (c) indicates instrumental problems that invalidate the measurement; $\mathrm{NA}=$ not available.

a Sample from Hole $756 \mathrm{C}$. 


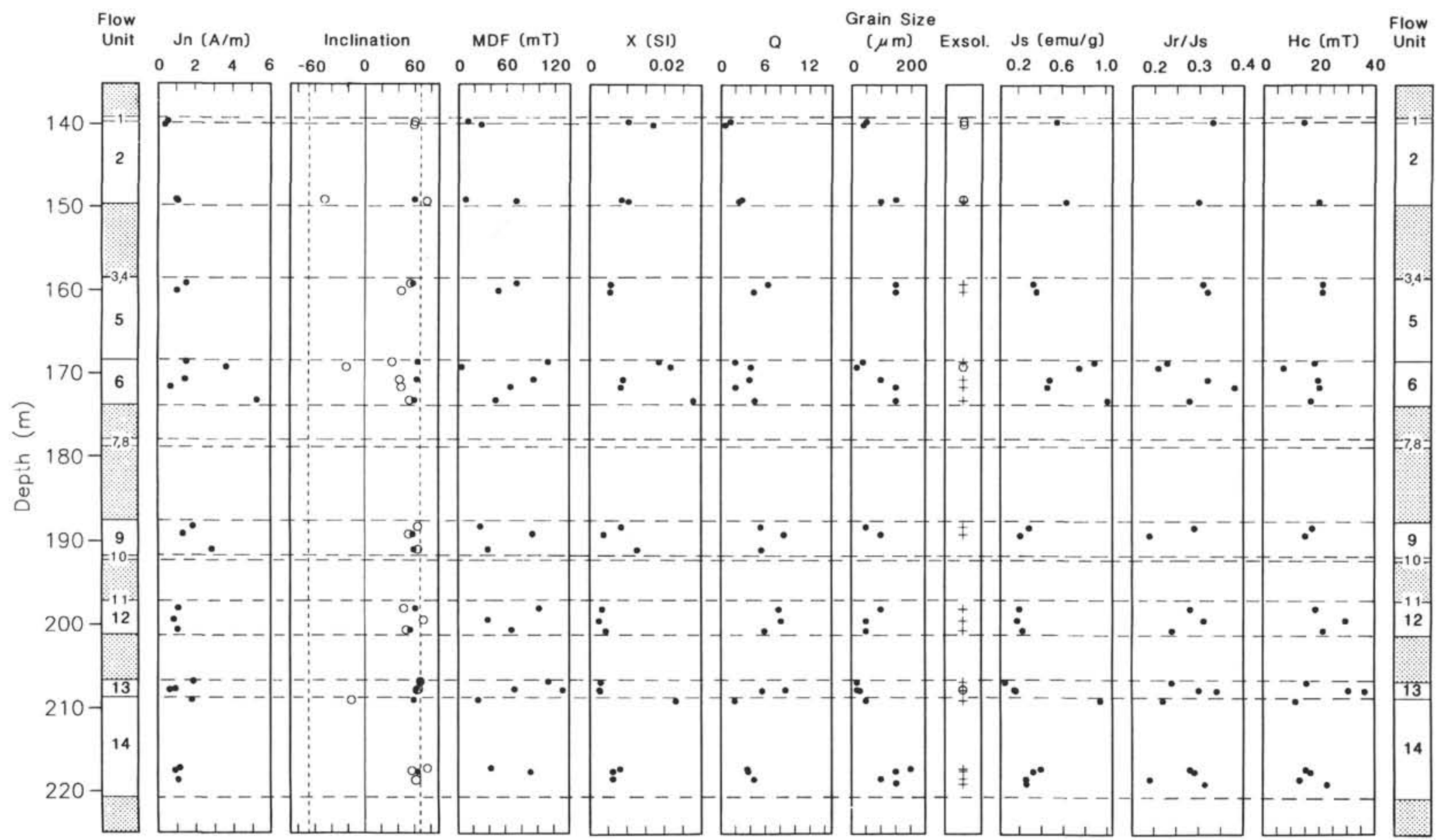

Figure 2. Magnetic, optical, and microprobe data from Site 756. Depth is in meters sub-bottom. An open symbol indicates the initial inclination; a solid symbol, final inclination. The dashed line gives the axial dipole inclination for the Kerguelen-Heard hot spot $\left(67^{\circ}\right)$. Exsol. indicates the presence $(+)$ or absence (circle) of exsolution lamellae. 


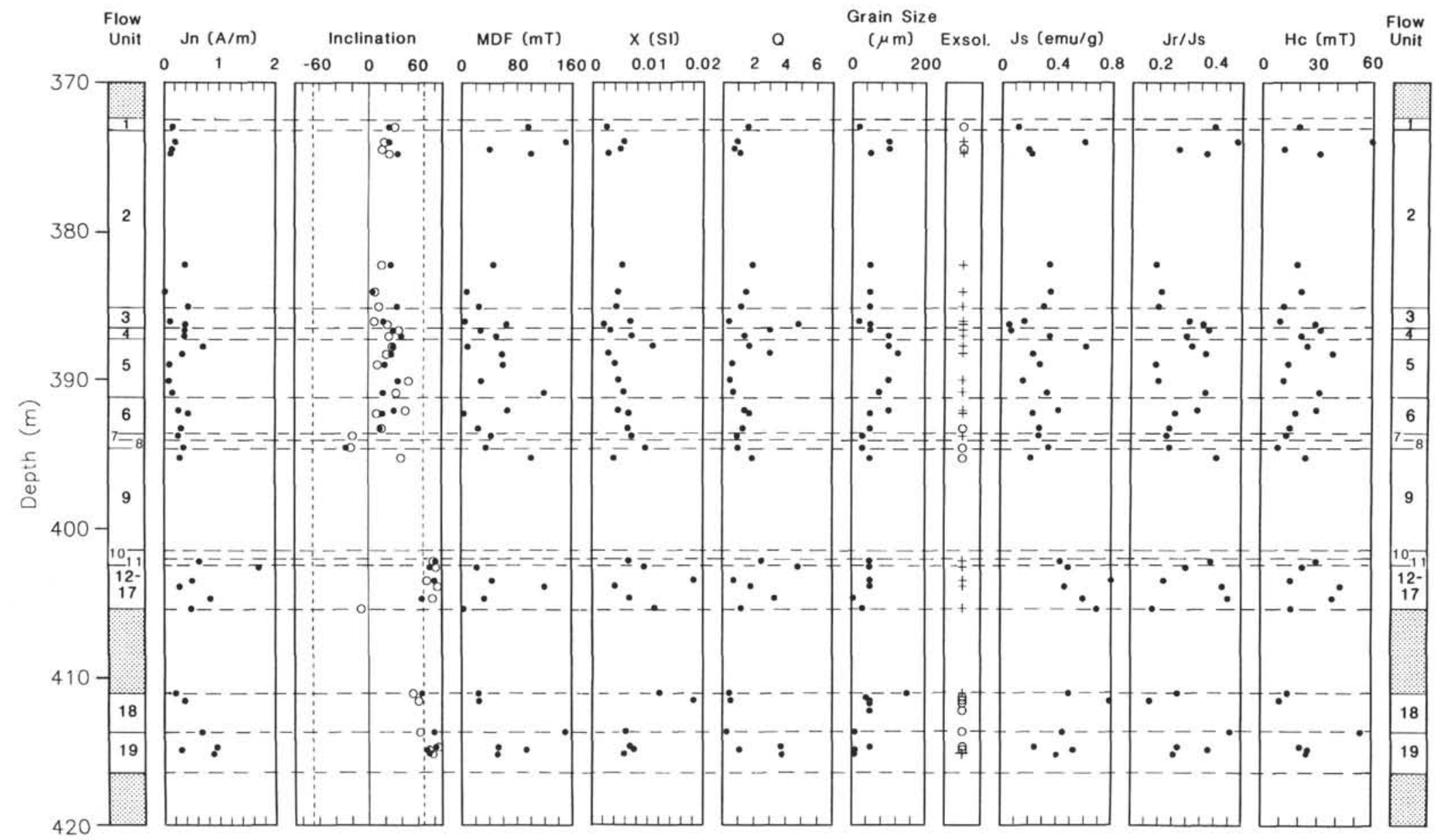

Figure 3. Magnetic, optical, and microprobe data from Site 757. Presentation of data the same as in Figure 2. 


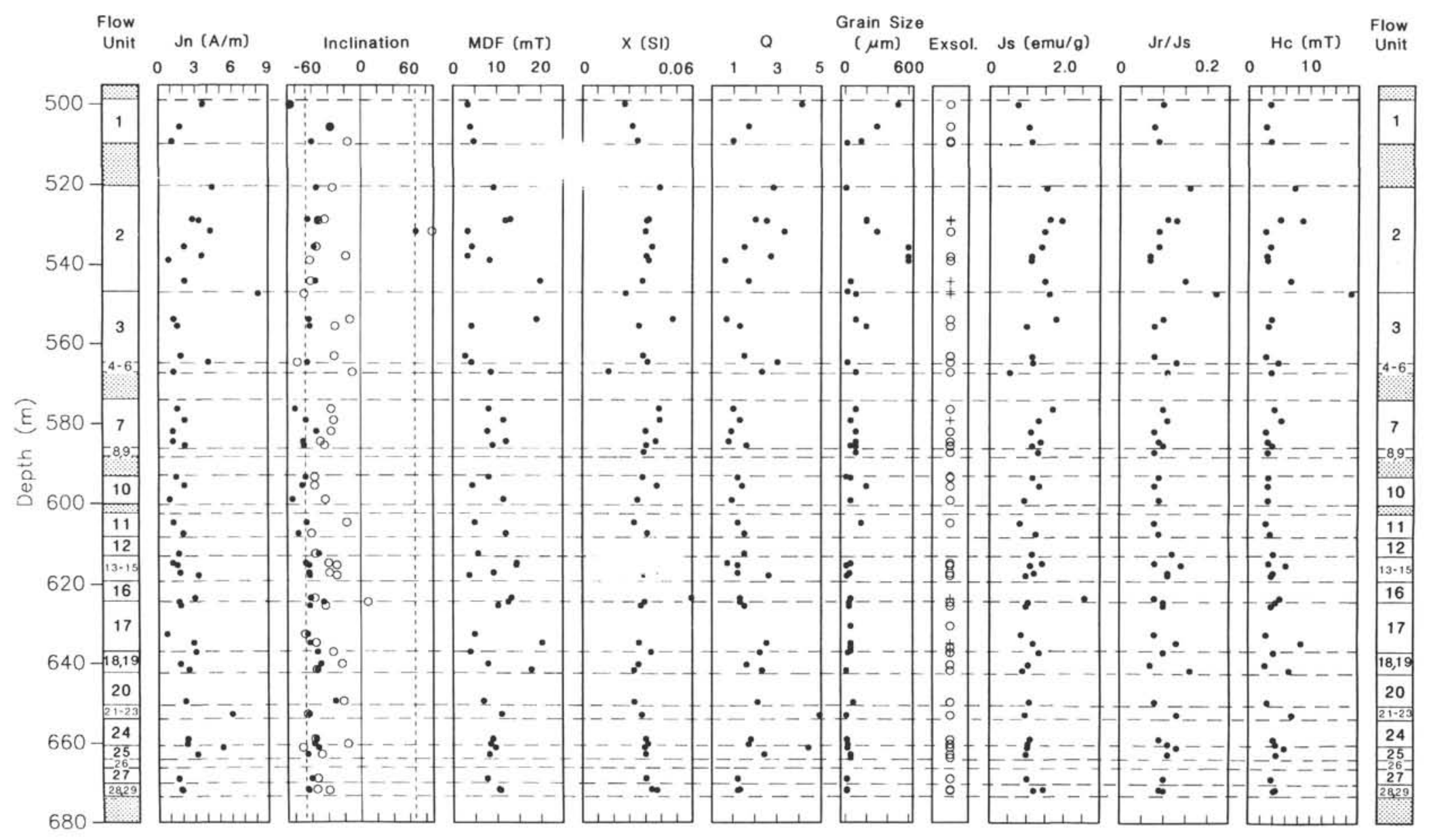

Figure 4. Magnetic, optical, and microprobe data from Site 758. Presentation of data the same as in Figure 2. 
Table 2. Average NRM, $Q$, and $\chi_{0}$ values for various seamounts.

\begin{tabular}{lllcl}
\hline \multicolumn{1}{c}{ Location } & $\begin{array}{c}\text { NRM } \\
\text { intensity } \\
(\mathrm{A} / \mathrm{m})\end{array}$ & \multicolumn{1}{c}{$\mathrm{Q}$} & $\left(\times 10^{-2}{ }^{\chi_{0}}\right.$ S.I. units $)$ & \multicolumn{1}{c}{ Reference } \\
\hline Jasper Seamount & $6.4(4.5)$ & $26.2(50.9)$ & ND & Gee et al. (1989) \\
a La Palma Island & $7.7(4.0)$ & $10.7(5.3)$ & 2.4 & Gee et al. (1988) \\
Nintoku Seamount & 5.6 & 6.1 & 3.0 & Kono (1980) \\
Suiko Seamount & 5.0 & 9.9 & 1.7 & Kono (1980) \\
Ojin Seamount & 4.7 & 5.8 & 2.5 & Kono (1980) \\
Meiji Seamount & 5.8 & 6.0 & 2.5 & Rice et al. (1979) \\
Seafloor basalt & 2.6 & 5.6 & 1.5 & Marshall et al. (1978) \\
Site 756 & $1.5(1.2)$ & $4.8(3.9)$ & $0.94(0.75)$ & \\
Site 757 & $0.43(0.32)$ & $1.7(1.3)$ & $0.79(0.68)$ & \\
Site 758 & $2.4(2.1)$ & $2.0(1.7)$ & $4.1(4.0)$ & \\
\hline
\end{tabular}

Note: The average values quoted are arithmetic means; available geometric means are in parentheses. ND $=$ not determined.

a Values quoted for the sub-greenschist facies extrusives only.

tion is used here in the sense of a stable high-coercivity component. The time of remanence acquisition may, in fact, postdate emplacement. This inclination is somewhat lower than expected from the Kerguelen-Heard hot spot $\left(50^{\circ} \mathrm{S}\right.$ latitude with an axial dipole inclination of $67^{\circ}$ ). Initial inclinations are generally shallower than stable values, which is consistent with the removal of a relatively shallow, low-coercivity viscous remanent magnetization (VRM). The MDFs are quite variable, ranging from less than $10 \mathrm{mT}$ to greater than $100 \mathrm{mT}$. In general, they are quite high, with an average of almost $70 \mathrm{mT}$. Initial susceptibility ranges from $2.58 \times 10^{-3}$ to $2.78 \times 10^{-2}$ (arithmetic mean, $9.42 \times 10^{-3}$; geometric mean, $\left.7.49 \times 10^{-3}\right)$. Koenigsberger ratios, calculated with the IGRF field for the site $(51,241 \mathrm{nT})$, vary from 0.6 to 15.5 (arithmetic mean, 4.8; geometric mean, 3.9), although all but two samples have ratios between 1 and 10 .

NRM magnitudes for Site 757 are lower than those for Site 756 by nearly a factor of 4 (arithmetic average, $0.431 \mathrm{~A} / \mathrm{m}$; geometric average, $0.324 \mathrm{~A} / \mathrm{m}$ ). Demagnetization was able to define primary magnetizations in many of the samples, but the inclinations were much lower than expected with samples taken above $400 \mathrm{~m}$ below seafloor (mbsf), generally at about $20^{\circ}$ (average, $21.1^{\circ}$ with an alpha 95 of $13^{\circ}$ ). Initial inclinations are both lower and higher than stable ones with no apparent pattern. The lowest $15 \mathrm{~m}$ shows much larger inclinations with some above $80^{\circ}$ (average, $76^{\circ}$ with an alpha 95 of $11^{\circ}$ ). The overall average was $39^{\circ}$ with an alpha 95 of $18^{\circ}$. As with the upper units, there is no consistent relationship between the initial and stable inclination, and although the inclinations are substantially higher than the expected $67^{\circ}$ all have shallow initial inclinations, indicating that these high values do not represent drilling-related remanence. MDFs are also highly variable, ranging from less than $5 \mathrm{mT}$ to more than $150 \mathrm{mT}$ (the current limit of the SLU AF demagnetizer). The average ( $56 \mathrm{mT}$ ) is somewhat lower than that of Site 756 but still quite high compared with that of seafloor basalts. Initial susceptibilities were only slightly lower than at Site 756 (arithmetic mean, 7.91 $\times 10^{-3}$; geometric mean, $\left.6.81 \times 10^{-3}\right)$. Koenigsberger ratios, on the other hand, were less than half (arithmetic mean, 1.7; geometric mean, 1.33).

The NRMs at Site 758 are the highest of the three sites, slightly less than a factor of 2 greater than those at Site 756 (arithmetic average, 2.36; geometric average, 2.10). Vector demagnetization plots are much more complex and commonly yielded poorly defined stable inclinations. Many samples showed no stable end point at all. Inclinations are generally between $50^{\circ}$ and $70^{\circ}$. The average was $-64^{\circ}$ with an alpha 95 of $6^{\circ}$, not significantly different from the expected $67^{\circ}$. Initial inclinations are usually shallower than the stable values and are consistent with the removal of a low-coercivity VRM with an inclination close to that ex- pected for the site. MDFs are generally low $(<5 \mathrm{mT})$ and none are greater than $20 \mathrm{mT}$ (mean, $9.2 \mathrm{mT}$ ). NRM and demagnetization behavior are discussed in much more detail in Klootwijk et al. (this volume). Initial susceptibility is roughly 4 times that of the other two sites (arithmetic mean, $4.05 \times 10^{-2}$; geometric mean, $3.97 \times 10^{-2}$ ) with most values tightly clustered about $4.0 \times 10^{-2}$. Koenigsberger ratios are fairly low (arithmetic average, 2.0; geometric average, 1.7), comparable to those of Site 757.

\section{Hysteresis Loop Measurements}

Hysteresis loop measurements involve measuring the behavior of the magnetization of a sample while a static field is slowly swept over a large field range (typically $\pm 0.8-1.0 \mathrm{~T}$ ). The measurements result in a characteristic graph, a schematic example of which is shown in Figure 5. These graphs are commonly reduced to three or four characteristic parameters. We have measured three: the saturation magnetization $\left(\mathrm{J}_{\mathrm{S}}\right)$, the saturation remanence $\left(\mathrm{J}_{\mathrm{r}}\right)$, and the coercivity $\left(\mathrm{H}_{\mathrm{C}}\right)$. The coercivity of remanence was not determined. The saturation magnetization is the maximum magnetization the sample can have (exclusive of paramagnetic com-

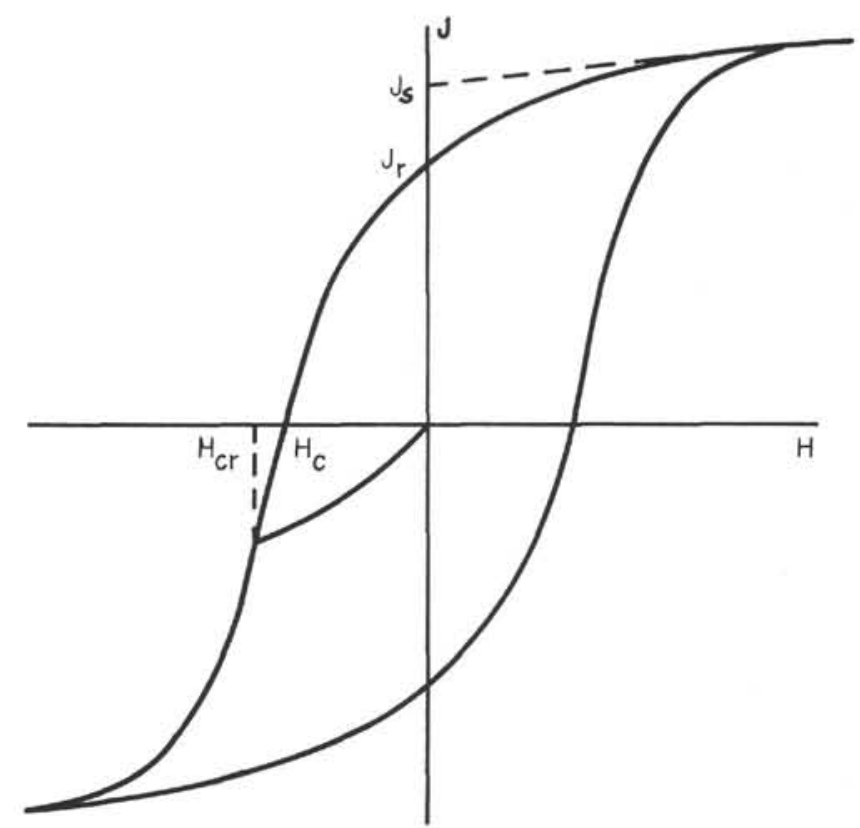

Figure 5. A schematic example of a hysteresis loop showing the definition of saturation magnetization $\left(\mathrm{J}_{\mathrm{s}}\right)$, saturation remanence $\left(\mathrm{J}_{\mathrm{r}}\right)$, and coercivity $\left(\mathrm{H}_{\mathrm{c}}\right)$. 
ponents) and is a measure of the amount of magnetic carrier present. Saturation remanence is the magnetization remaining when the applied field is returned to zero after saturation of the sample. It is normally found as the ratio $\mathrm{J}_{\mathrm{r}} / \mathrm{J}_{\mathrm{s}}$, which is related to domain state and hence grain size. Conventionally, a $\mathrm{J}_{\mathrm{r}} / \mathrm{J}_{\mathrm{S}}$ of $0.5-0.8$ is taken to indicate single domain grains and a $J_{\mathrm{r}} / \mathrm{J}_{\mathrm{S}}$ less than $0.1-0.2$ to indicate multidomain material (e.g., Day et al., 1976). The intermediate range is generally called the pseudosingle domain, although the mechanism of magnetization is not well understood. The coercivity is the field necessary to reduce the magnetization of a saturated sample to zero. As the magnetization thus measured includes both remanent and induced components, interpretation is often problematical, but $\mathrm{H}_{\mathrm{c}}$ is a rough measure of magnetic stability. It is generally less than the MDF. Interpretation of the latter two parameters is complicated by such factors as mixtures of different grain sizes, variable composition, and the presence of exsolution, one or more of which are found in many of the samples discussed here. Exsolution and the presence of hematite both tend to increase $\mathrm{J}_{\mathrm{r}} / \mathrm{J}_{\mathrm{S}}$ and $\mathrm{H}_{\mathrm{c}}$. Hysteresis loop parameters for the three sites are summarized in Table 3.

Site $756 \mathrm{~J}_{\mathrm{s}}$ values are generally between 0.1 and $1.0 \mathrm{~A} / \mathrm{m}^{2}-\mathrm{kg}$ with an average value of $0.39 \mathrm{~A} / \mathrm{m}^{2}-\mathrm{kg}\left(1 \mathrm{~A} / \mathrm{m}^{2}-\mathrm{kg}=1 \mathrm{emu} / \mathrm{g}\right)$. If a composition of pure magnetite is assumed for the magnetic carrier, this corresponds to $0.4 \%$ magnetite in the rocks. The $\mathrm{J}_{\mathrm{r}} / \mathrm{J}_{\mathrm{S}}$ values are in the 0.2 to 0.3 range (average, 0.29 ), corresponding to a pseudosingle domain state. Coercivities are largely between 10 and $30 \mathrm{mT}$. There appears to be no systematic variation within the section for any of these parameters.

Site $757 \mathrm{~J}_{\mathrm{s}}$ values are largely between 0.1 and $0.5 \mathrm{~A} / \mathrm{m}^{2}-\mathrm{kg}$ with an average of $0.35 \mathrm{~A} / \mathrm{m}^{2}-\mathrm{kg}$, equivalent to $0.4 \%$ pure magnetite. The $\mathrm{J}_{\mathrm{r}} / \mathrm{J}_{\mathrm{s}}$ values are somewhat higher than those of Site 757, ranging from 0.2 to nearly 0.5 (average, 0.30 ), toward the high end of the pseudosingle domain range. $\mathrm{H}_{\mathrm{c}}$ is also somewhat higher than at Site 756, with some values in excess of $40 \mathrm{mT}$ and an average of $24 \mathrm{mT}$. There is some tendency for all three parameters to be larger near the tops of the flow units, but there are no apparent overall trends.

Site $758 \mathrm{~J}_{\mathrm{s}}$ values are the highest of the three sites, generally in excess of $1.0 \mathrm{~A} / \mathrm{m}^{2}-\mathrm{kg}$ (average, $1.22 \mathrm{~A} / \mathrm{m}^{2}-\mathrm{kg}$ ), corresponding to $1.3 \%$ pure magnetite. $\mathrm{J}_{\mathrm{r}} / \mathrm{J}_{\mathrm{S}}$ values are generally low, with virtually all less than 0.2 and many below 0.1 (average, 0.10 ), indicating multidomain material. $\mathrm{H}_{\mathrm{c}}$ values are also low, with all but one falling below $10 \mathrm{mT}$ and most less than $5 \mathrm{mT}$ (average, $4.7 \mathrm{mT}$ ). There seems to be a tendency in the thick upper flows for $J_{S}$ to be lower at the top of the flow than the center, with $J_{r} / J_{S}$ and $\mathrm{H}_{\mathrm{c}}$ higher. There are not enough samples in the lower units to determine such trends. $\mathrm{J}_{\mathrm{S}}$ is somewhat lower below $600 \mathrm{mbsf}$, where the flows are thinner, but the other two parameters show no apparent overall trend with depth.

\section{OPTICAL AND MICROPROBE RESULTS}

Magnetic measurements alone do not provide complete information about the magnetic mineralogy. In most cases, the values of magnetic parameters can be produced by a variety of mechanisms. For example, mixtures of grain sizes can mimic the hysteresis loop behavior of a narrow and different grain-size range. In addition, some factors are difficult or impossible to detect magnetically. The addition of a small amount of hematite or ilmenite to a magnetite-bearing assemblage will have an almost unnoticeable affect on intrinsic magnetic properties but gives important information on alteration history and may carry significant remanence. Many of these ambiguities can be resolved by microscopic examination of the samples. Examination of polished sections allows the determination of grain size and the degree and type of alteration and gives a general understanding of mineralogy. The addition of electron microprobe analysis yields accurate compo- sitions of selected regions of individual grains. This information is especially useful for understanding alteration state and history, as magnetic measurements commonly give either ambiguous information or none at all.

The most important magnetic minerals found in igneous rocks can be summarized in a ternary diagram (Fig. 6). The primary magnetic minerals fall on one of the two solid-solution series: the cubic magnetite-ulvöspinel (titanomagnetite) series or the rhombohedral ilmenite-hematite (hemoilmenite) series. The compositions are $\mathrm{Fe}_{3-x} \mathrm{Ti}_{x} \mathrm{O}_{4}$ and $\mathrm{Fe}_{2-x} \mathrm{Ti}_{x} \mathrm{O}_{3}$, respectively, and are commonly referred to in terms of their $x$-value. Basaltic compositions normally contain primary magnetite and ilmenite either as separate grains or, less commonly, as different regions of a single grain.

Oxidation of primary titanomagnetite can produce compositions to the right of the solid-solution line. When oxidation occurs at low temperatures (below $150^{\circ} \mathrm{C}$ or so), the result is a singlephase material similar to the original titanomagnetite (titanomaghemite) but with cation vacancies corresponding to the degree of oxidation. This process appears to involve the loss of iron (e.g., Worm and Banerjee, 1984), which causes a reduction in grain volume. This shrinkage leads in turn to cracking of the grains, which is a characteristic optical indicator of this type of alteration (Pl. 1, Fig. 1). Higher grades of low-temperature alteration cause additional changes that are also optically recognizable (e.g., Ade-Hall et al., 1971, Johnson and Hall, 1978). We have classified our samples as low, medium, and high. In terms of Johnson and Hall (1978), low corresponds to stage one or lower stage two, medium to stage two, and high to stage three or perhaps the lowest part of stage four. As the kinetics of oxidation at these temperatures may be quite slow with equilibrium rare, the alteration grade is an uncertain function of age and temperature. Magnetically, such alteration tends to reduce NRM intensity and raise both the magnetic stability and Curie temperature.

High-temperature alteration in the classic sense is commonly referred to as deuteric alteration. It occurs above about $600^{\circ} \mathrm{C}$ and

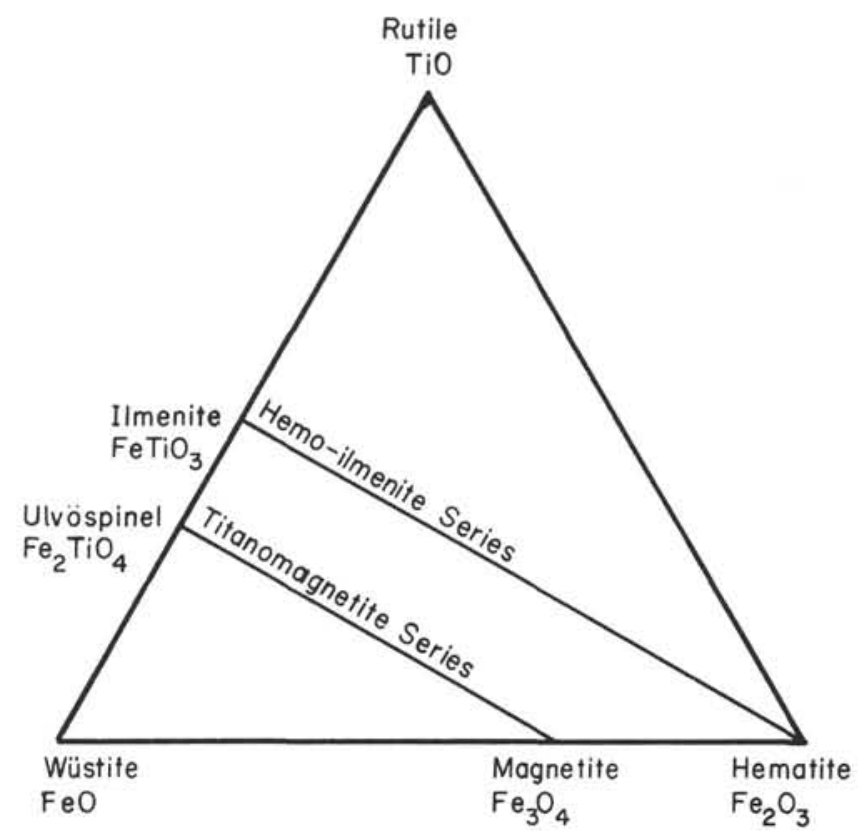

Figure 6. The magnetically important $\mathrm{Fe}$ - $\mathrm{Ti}$ oxides on a Fe-Ti-O ternary diagram (from Merrill and McElhinny, 1983). 
is generally thought to take place during cooling (e.g., Haggerty, 1976). This type of alteration causes exsolution of primary titanomagnetite into two or more phases. The principle phases are usually a low-Ti titanomagnetite and a high-Ti hemoilmenite with only the former phase magnetic. The exsolved phases are commonly simply called magnetite and ilmenite, as they are generally close to end-member compositions. They are more accurately referred to as spinel and rhombohedral phases.

Exsolution commonly takes place on the (111) planes of the primary titanomagnetite. Because the two phases have different optical characters, a characteristic pattern of lamellae, called a trellis pattern (P1. 1, Fig. 2), is usually readily apparent (Haggerty, 1976). This pattern is distinctly different from primary magnetite-ilmenite combinations, which generally involve larger regions without the characteristic (111) crystallographic control (Pl. 1, Fig. 3). In addition to the optically visible changes, exsolution is also indicated by a mismatch between the bulk composition (as determined by microprobe measurements) and the Curie temperature (a measure of the composition of the exsolved spinel phase). The magnetic effect of exsolution is to raise the magnetic stability of the primary titanomagnetite (e.g., Tucker and O'Reilly, 1980). As the temperature at which the process occurs is above the Curie point of pure magnetite, the result is a purely thermal remanence that dates from the time of deposition. Exsolution can also occur without producing visible lamellae. It is detected by comparing the Curie temperature predicted from the microprobe-determined composition to that actually measured. Results from the transition zone and upper part of the dike complex of DSDP Hole 504B show optically homogeneous titanomagnetites with microprobe-determined bulk compositions of $x=0.6-0.7$ but with Curie temperatures indicating values close to $x=0.0$ (Smith and Banerjee, 1986). This can only be explained by exsolution on a scale too fine to be optically resolvable (e.g., Evans and Wayman, 1974). It may take place at temperatures above the stability limit for the cation-deficient phase $\left(300^{\circ}-400^{\circ} \mathrm{C}\right)$ but far enough below $600^{\circ} \mathrm{C}$ to prevent formation of visible lamellae. Smith and Banerjee (1986) favored hydrothermal alteration as the agent rather than deuteric oxidation, but the model has not been tested experimentally. Suboptical exsolution has also been observed in samples from the Bermuda Seamount (Rice et al., 1980). The phenomenon may, in fact, be relatively common, but the necessary combination of microprobe and thermomagnetic analysis is not usually performed.

Most of the samples discussed in the previous section, as well as chips from some of the samples collected by C. Klootwijk (see Klootwijk et al., this volume), were examined microscopically. Nineteen samples were also chosen for electron microprobe study. The samples were measured on a three-channel JEOL superprobe. Nominal spot size was generally $1 \mu \mathrm{m}(3-4 \mu \mathrm{m}$ in practice). Exsolved samples were measured with a $10-\mu \mathrm{m}$ spot size to ensure a true bulk value. An EDAX scan was run on very small grains to ensure that the measurement did not include surrounding silicates. $\mathrm{Fe}$ and $\mathrm{Ti}$ were calibrated with an ilmenite standard, as the olivine standard commonly used for silicate measurements tends to give poor results for oxides. $\mathrm{Fe}, \mathrm{Ti}, \mathrm{Al}, \mathrm{Mg}$, and $\mathrm{Mn}$ were measured initially. $\mathrm{Mg}$ and $\mathrm{Mn}$ concentrations were generally no more than 1 to 2 cation percent. Al was commonly about 5 cation percent. As time was limited, some of the samples were probed only for $\mathrm{Fe}, \mathrm{Ti}$, and $\mathrm{Al}$ (the latter was the most abundant trace element observed in the first batch of measurements). The $x$-value listed in Table 4 is calculated from $\mathrm{Fe}$ and $\mathrm{Ti}$ only.

The principle goals of the optical examination were a rough determination of grain size, alteration state, and the presence of secondary phases related to alteration. Microprobe studies provided accurate composition measurements. These measurements are summarized in the tables. Ideally these studies would be complemented by thermomagnetic studies to determine the Curie temperature. Equipment problems prevented making these measurements in time for this publication, and they will be presented in a future publication.

Site 756 basalts were characterized by an abundance of primary ilmenite, which amounted to about $80 \%$ of the total opaque minerals. Grain sizes were generally $50 \mu \mathrm{m}$ and greater, although a few samples were in the $20-50-\mu \mathrm{m}$ range. Titanomagnetite was found as isolated grains or sporadically combined with primary ilmenite. Many of the ilmenite grains also were extensively veined and/or rimmed with a light-colored mineral (PI. 1, Fig. 4). The veined ilmenite grains appear very similar to alteration grade R3 of Haggerty (1976), who identified the light veins as rutile. The composition of the rimming mineral is not known. The majority of the titanomagnetite grains (including those that are combined with primary ilmenite) are exsolved, although a few are optically homogeneous at $1200 \times$ (principally in flow Units $756 \mathrm{D}-\mathrm{F} 1$ and $756 \mathrm{D}-\mathrm{F} 2$ ). Low-temperature alteration, as indicated by the amount of cracking, was low to moderate. The brownish color of the rocks suggests the presence of secondary iron oxides disseminated throughout the rock matrix, although such "pigment" phases are generally too small to be optically resolvable. Some samples did contain microscopically visible hematite, either as a distinct secondary phase or replacing primary titanomagnetite.

The primary oxide mineralogy of the Site 757 basalts was dominated by titanomagnetite. Grain sizes ranged from barely visible to large (about 5 to $150 \mu \mathrm{m}$ ). Habits were commonly dendritic and commonly quite complex (Pl. 1, Fig. 5), making the determination of grain size a bit difficult (tabulated grain sizes refer to the whole grain, not the individual branches). The majority of the samples showed visible exsolution, and some samples had dendritic habits (Pl. 1, Fig. 5). Several samples did not show visible exsolution, however, especially flow Units 757C-F18 and $757 \mathrm{C}-\mathrm{F} 19$ at the bottom of the hole. Cracking was generally light to moderate. Most of the samples were red or reddish brown, suggesting the presence of disseminated pigment hematite. Hematite was also microscopically visible in many samples, either as distinct secondary phases or replacing primary titanomagnetite. Although some of the dark samples contained exsolved titanomagnetite, none had any visible secondary hematite.

The primary oxide mineralogy of the Site 758 basalts was also dominated by titanomagnetite. Grain sizes ran as high as $600 \mu \mathrm{m}$ in the interiors of the thick flows near the top of basement but decreased to $50 \mu \mathrm{m}$ or less in the thin flow and pillow units toward the bottom of the hole. Habits were commonly dendritic, although much more filled-in than those of Site 757 . They were generally also much less complex. The majority of the samples did not have visible exsolution lamellae, and those that did tended to be toward the top of the section and near the margins of the flows. Cracking was much more extensive and common than at the other two sites, indicating a greater degree of low-temperature alteration (stage 2 or 3 of Johnson and Hall, 1978) with some samples showing evidence of granulation (e.g., Pl. 1, Fig. 1). Samples were generally dark and secondary hematite was not observed.

The results of the microprobe analysis of 19 samples are shown in Table 4 and summarized in Figure 7. These results are mostly the bulk compositions of the primary oxides, as the lamellae were generally spaced too closely to get separate measurements of the spinel and rhombohedral phases. These values should thus reflect the original oxide composition, prior to exsolution, although a few percent $\mathrm{Fe}$ may have been lost to low-temperature alteration. Some ilmenite grains were probed as well. The raw data showed 
Table 3. Hysteresis loop and some optical data from Sites 756, 757, and 758.

\begin{tabular}{|c|c|c|c|c|c|c|c|}
\hline $\begin{array}{l}\text { Core, section, } \\
\text { interval }(\mathrm{cm})\end{array}$ & $\begin{array}{l}\text { Depth } \\
\text { (mbsf) }\end{array}$ & $\begin{array}{l}\text { Flow } \\
\text { unit }\end{array}$ & $\begin{array}{c}\text { Grain } \\
\text { size } \\
(\mu \mathrm{m})\end{array}$ & $\frac{J_{s}}{(e m u / g)}$ & $\begin{array}{c}\mathrm{J}_{\mathrm{r}} \\
(\mathrm{emu} / \mathrm{g})\end{array}$ & $\mathrm{Jr} / \mathrm{JS}$ & $\begin{array}{c}\mathrm{H}_{\mathrm{c}} \\
(\mathrm{mT})\end{array}$ \\
\hline $4 \mathrm{R}-1,47-49$ & 139.5 & F1 & 50 & 0.54 & 0.18 & 0.33 & 14.5 \\
\hline $4 \mathrm{R}-1,90-92$ & 139.9 & F2 & 40 & (a) & (a) & (a) & (a) \\
\hline $5 R-1,25-27$ & 148.9 & F2 & 150 & (a) & (a) & (a) & (a) \\
\hline $5 \mathrm{R}-1,46-48$ & 149.1 & $\mathrm{~F} 2$ & 100 & 0.63 & 0.19 & 0.30 & 20.1 \\
\hline${ }^{a} 10 N-1,27-29$ & 150.6 & F1 & 50 & 0.216 & $7.09 \mathrm{e}-2$ & 0.33 & 13.1 \\
\hline${ }^{a} 10 N-3,82-84$ & 154.1 & F1 & 100 & 0.191 & $6.54 \mathrm{e}-2$ & 0.34 & 14.4 \\
\hline $6 \mathrm{R}-1,73-75$ & 159.0 & F5 & 150 & 0.33 & 0.10 & 0.31 & 21.5 \\
\hline $6 R-2,5-7$ & 159.9 & F5 & 150 & 0.36 & 0.12 & 0.32 & 21.4 \\
\hline $7 R-1,41-43$ & 168.4 & F6 & 40 & 0.89 & 0.21 & 0.23 & 18.6 \\
\hline $7 \mathrm{R}-1,104-106$ & 169.0 & F6 & 20 & 0.75 & 0.16 & 0.21 & 7.5 \\
\hline $7 R-2,98-100$ & 170.5 & F6 & 100 & 0.48 & 0.15 & 0.32 & 19.8 \\
\hline 7R-3, 47-49 & 171.4 & F6 & 150 & 0.46 & 0.18 & 0.38 & 20.3 \\
\hline $7 R-4,65-67$ & 173.0 & F6 & 150 & 1.01 & 0.29 & 0.28 & 17.2 \\
\hline $9 \mathrm{R}-1,71-73$ & 188.1 & F9 & 50 & 0.29 & $8.5 e-2$ & 0.29 & 17.7 \\
\hline $9 R-2,32-34$ & 189.0 & F9 & 100 & 0.21 & $4.0 \mathrm{e}-2$ & 0.19 & 15.2 \\
\hline $10 \mathrm{R}-1,94-96$ & 197.9 & F12 & 100 & 0.20 & $5.7 e-2$ & 0.28 & 18.7 \\
\hline $10 \mathrm{R}-2,84-86$ & 199.3 & F12 & 50 & 0.18 & $5.5 \mathrm{e}-2$ & 0.31 & 29.5 \\
\hline $10 \mathrm{R}-3,46-48$ & 200.5 & F12 & 50 & 0.23 & $5.4 \mathrm{e}-2$ & 0.24 & 21.5 \\
\hline $11 \mathrm{R}-1,7-9$ & 206.7 & F13 & 20 & $7.3 e-2$ & $1.77 \mathrm{e}-2$ & 0.24 & 15.7 \\
\hline $11 \mathrm{R}-1,97-99$ & 207.6 & F13 & 20 & 0.157 & $4.71 e-2$ & 0.30 & 30.6 \\
\hline $11 \mathrm{R}-1,110-112$ & 207.7 & F13 & 30 & 0.170 & $5.78 \mathrm{e}-2$ & 0.34 & 36.4 \\
\hline $11 \mathrm{R}-2,84-86$ & 208.9 & F14 & 50 & 0.942 & 0.212 & 0.22 & 11.7 \\
\hline $12 \mathrm{R}-1,86-88$ & 217.1 & F14 & 200 & 0.396 & 0.108 & 0.28 & 15.3 \\
\hline $12 \mathrm{R}-2,3-5$ & 217.4 & F14 & 150 & 0.326 & $9.55 \mathrm{e}-2$ & 0.29 & 17.0 \\
\hline $12 \mathrm{R}-2,92-94$ & 218.3 & F14 & 100 & 0.261 & $4.89 \mathrm{e}-2$ & 0.19 & 13.1 \\
\hline $12 \mathrm{R}-3,25-27$ & 219.1 & F14 & 150 & 0.271 & $8.73 e-2$ & 0.32 & 19.6 \\
\hline \multicolumn{8}{|l|}{$121-757 C$} \\
\hline $8 \mathrm{R}-1,69-71$ & 373.0 & F1 & 20 & 0.121 & $4.85 \mathrm{e}-2$ & 0.40 & 20.2 \\
\hline $8 \mathrm{R}-1,122-124$ & 374.0 & F2 & 100 & 0.596 & 0.288 & 0.48 & 59.1 \\
\hline $8 R-2,61-63$ & 374.5 & F2 & 100 & 0.194 & $5.15 e-2$ & 0.27 & 12.0 \\
\hline $8 \mathrm{R}-2,89-91$ & 374.8 & F2 & 50 & 0.216 & $8.09 \mathrm{e}-2$ & 0.37 & 31.2 \\
\hline $9 \mathrm{R}-1,26-28$ & 382.3 & F2 & 50 & 0.348 & $6.65 \mathrm{e}-2$ & 0.19 & 19.4 \\
\hline $9 \mathrm{R}-2,92-94$ & 384.1 & $\mathrm{~F} 2$ & 50 & 0.356 & $7.56 \mathrm{e}-2$ & 0.21 & 21.8 \\
\hline $9 \mathrm{R}-3,98-100$ & 385.1 & F2 & 50 & 0.309 & $6.14 \mathrm{e}-2$ & 0.20 & 12.4 \\
\hline $9 \mathrm{R}-4,69-71$ & 386.1 & F3 & 20 & 0.167 & $5.17 \mathrm{e}-2$ & 0.31 & 10.2 \\
\hline $9 \mathrm{R}-4,86-88$ & 386.3 & F3 & so & $5.92 \mathrm{e}-2$ & $2.13 \mathrm{e}-2$ & 0.36 & 29.1 \\
\hline $9 \mathrm{R}-4,127-129$ & 386.7 & F4 & 50 & $7.3 e-2$ & $2.8 \mathrm{e}-2$ & 0.38 & 32.0 \\
\hline $9 R-5,31-33$ & 387.1 & F4 & 100 & 0.35 & 0.10 & 0.30 & 21.7 \\
\hline $9 \mathrm{R}-6,20-22$ & 387.8 & F5 & 100 & 0.61 & 0.20 & 0.32 & 25.0 \\
\hline $9 R-6,66-68$ & 388.3 & F5 & 125 & 0.231 & $8.62 \mathrm{e}-2$ & 0.37 & 38.6 \\
\hline $9 \mathrm{R}-7,25-27$ & 389.0 & F5 & (a) & 0.281 & $5.44 \mathrm{e}-2$ & 0.19 & 14.9 \\
\hline $9 \mathrm{R}-7,136-138$ & 390.1 & F5 & 100 & 0.161 & $3.28 \mathrm{e}-2$ & 0.20 & 12.4 \\
\hline $9 \mathrm{R}-8,71-73$ & 390.9 & F5 & 75 & 0.334 & 0.123 & 0.37 & 31.6 \\
\hline 10R-1, 39-41 & 392.1 & F6 & 100 & 0.413 & 0.141 & 0.34 & 29.9 \\
\hline $10 \mathrm{R}-1,61-63$ & 392.3 & F6 & 50 & 0.230 & $5.97 \mathrm{e}-2$ & 0.26 & 18.6 \\
\hline $10 \mathrm{R}-2,20-22$ & 393.3 & F6 & 50 & 0.278 & $6.79 \mathrm{e}-2$ & 0.24 & 15.7 \\
\hline $10 \mathrm{R}-2,70-72$ & 393.8 & F7 & 30 & 0.274 & $6.32 \mathrm{e}-2$ & 0.23 & 13.8 \\
\hline $10 \mathrm{R}-3,7-9$ & 394.6 & F8 & 30 & 0.344 & 0.23 & 0.24 & 9.3 \\
\hline $10 \mathrm{R}-3,77-79$ & 395.3 & F9 & 50 & 0.218 & $8.97 \mathrm{e}-2$ & 0.41 & 24.2 \\
\hline $11 \mathrm{R}-1,78-80$ & 402.2 & F10 & 50 & 0.432 & 0.167 & 0.39 & 30.0 \\
\hline $11 R-1,115-117$ & 402.6 & F11 & 50 & 0.490 & 0.149 & 0.30 & 22.6 \\
\hline $11 \mathrm{R}-2,49-51$ & 403.5 & F13 & 50 & 0.812 & 0.182 & 0.22 & 16.1 \\
\hline $11 R-2,100-102$ & 403.9 & F14 & 50 & 0.461 & 0.200 & 0.43 & 42.8 \\
\hline $11 \mathrm{R}-3,47-49$ & 404.7 & F16 & 5 & 0.592 & 0.264 & 0.45 & 38.5 \\
\hline $11 \mathrm{R}-3,115-117$ & 405.4 & F17 & 30 & 0.692 & 0.125 & 0.18 & 16.4 \\
\hline $12 \mathrm{R}-1,2-4$ & 411.1 & F18 & 150 & 0.490 & 0.133 & 0.27 & 14.6 \\
\hline $12 \mathrm{R}-1,30-32$ & 411.4 & F18 & 40 & (a) & (a) & (a) & (a) \\
\hline $12 \mathrm{R}-1,53-55$ & 411.6 & F18 & 50 & 0.783 & 0.134 & 0.17 & 10.3 \\
\hline $12 R-1,65-67$ & 411.8 & F18 & 50 & (a) & (a) & (a) & (a) \\
\hline $12 \mathrm{R}-1,117-119$ & 412.3 & F18 & 50 & (a) & (a) & (a) & (a) \\
\hline $12 \mathrm{R}-3,8-10$ & 413.7 & F19 & 10 & 0.447 & 0.206 & 0.46 & 53.8 \\
\hline $12 \mathrm{R}-3,108-110$ & 414.7 & F19 & 50 & 0.243 & $6.57 \mathrm{e}-2$ & 0.27 & 21.0 \\
\hline $12 \mathrm{R}-3,127-129$ & 414.9 & F19 & 10 & 0.522 & 0.196 & 0.38 & 25.3 \\
\hline $12 \mathrm{R}-3,132-134$ & 415.0 & F19 & 5 & 0.386 & $9.95 \mathrm{e}-2$ & 0.26 & 24.8 \\
\hline
\end{tabular}

totals significantly less than $100 \%$. The most likely explanation is the presence of vacancies due to low-temperature alteration, which was optically observed in most samples.

Site 756 had a relatively broad distribution ranging from $x=$ 0.24 to 0.88 . The $x=0.24$ value (spot 1 of Sample 121-756D$7 \mathrm{R}-1,41-43 \mathrm{~cm})$ is anomalously low and may not represent bulk values. All other grains from this sample had large regions of magnetite between lamellae and the other measurements reflect the composition of the spinel phase only. The similarity of the other measurements in spot 1 to those of the other samples and the fact that the visible grain was small suggest that the grain may be exsolved and but by chance did not have any lamellae exposed. 
Table 3 (continued).

\begin{tabular}{|c|c|c|c|c|c|c|c|}
\hline $\begin{array}{l}\text { Core, section, } \\
\text { interval }(\mathrm{cm})\end{array}$ & $\begin{array}{l}\text { Depth } \\
\text { (mbsf) }\end{array}$ & $\begin{array}{l}\text { Flow } \\
\text { unit }\end{array}$ & $\begin{array}{c}\text { Grain } \\
\text { size } \\
(\mu \mathrm{m})\end{array}$ & $\begin{array}{c}\mathrm{J}_{\mathrm{s}} \\
(\mathrm{emu} / \mathrm{g})\end{array}$ & $\begin{array}{c}\mathrm{J}_{\mathrm{r}} \\
(\mathrm{emu} / \mathrm{g})\end{array}$ & $\mathrm{Jr} / \mathrm{Js}$ & $\underset{(\mathrm{mT})}{\mathrm{H}_{\mathrm{c}}}$ \\
\hline \multicolumn{8}{|l|}{$121-758 \mathrm{~A}-$} \\
\hline 55R-1, 94-96 & 499.84 & F1 & 500 & 0.77 & 0.08 & 0.10 & 3.7 \\
\hline 55R-5, 86-88 & 505.43 & F1 & 300 & 1.07 & 0.08 & 0.08 & 3.0 \\
\hline $56 \mathrm{R}-1,69-71$ & 509.09 & F1 & 150 & 1.15 & 0.10 & 0.09 & 3.8 \\
\hline 56R-1, 113-117 & 509.53 & F1 & 15 & (a) & (a) & (a) & (a) \\
\hline S7R-3, 15-17 & 520.76 & $\mathrm{~F} 2$ & 5 & 1.54 & 0.24 & 0.16 & 7.6 \\
\hline $58 \mathrm{R}-2,15-17$ & 528.70 & F2 & 200 & 1.63 & 0.17 & 0.11 & 5.3 \\
\hline $58 \mathrm{R}-2,44-46$ & 529.00 & $\mathrm{~F} 2$ & 200 & 1.95 & 0.26 & 0.13 & 8.9 \\
\hline $58 \mathrm{R}-4,14-16$ & 531.69 & $\mathrm{~F} 2$ & 300 & 1.49 & 0.13 & 0.09 & 2.9 \\
\hline $58 R-6,137-139$ & 535.54 & F2 & 600 & 1.41 & 0.13 & 0.09 & 3.7 \\
\hline $59 \mathrm{R}-1,136-138$ & 537.86 & $\mathrm{~F} 2$ & 600 & 1.14 & 0.08 & 0.07 & 3.1 \\
\hline 59R-2, 102-104 & 538.93 & $\mathrm{~F} 2$ & 600 & 1.13 & 0.08 & 0.07 & 3.2 \\
\hline $59 R-6,65-67$ & 544.10 & $\mathrm{~F} 2$ & 50 & 1.50 & 0.22 & 0.15 & 7.0 \\
\hline $60 \mathrm{R}-1,74-75$ & 546.64 & $\mathrm{~F} 2$ & 20 & (a) & (a) & (a) & (a) \\
\hline $60 \mathrm{R}-2,12-14$ & 547.29 & F3 & 100 & 1.62 & 0.36 & 0.22 & 16.8 \\
\hline $60 \mathrm{R}-6,108-110$ & 553.76 & F3 & 100 & 1.80 & 0.18 & 0.10 & 3.9 \\
\hline $61 R-1,36-38$ & 555.46 & F3 & 200 & 1.01 & 0.08 & 0.08 & 3.4 \\
\hline $61 R-7,12-14$ & 562.97 & F3 & (a) & 1.16 & 0.10 & 0.08 & 3.0 \\
\hline $61 R-7,11-13$ & 563.02 & F3 & (a) & (a) & (a) & (a) & (a) \\
\hline $62 \mathrm{R}-1,25-27$ & 564.55 & F3 & 20 & 1.18 & 0.15 & 0.13 & 5.0 \\
\hline $62 \mathrm{R}-2,125-127$ & 567.01 & F4 & 100 & 0.56 & 0.06 & 0.11 & 3.9 \\
\hline $63 R-2,114-116$ & 576.26 & F7 & 100 & 1.72 & 0.16 & 0.10 & 4.4 \\
\hline $63 R-4,129-131$ & 579.06 & F7 & 50 & 1.34 & 0.14 & 0.11 & 5.5 \\
\hline $63 R-6,133-135$ & 581.88 & F7 & 100 & 1.13 & 0.09 & 0.08 & 3.0 \\
\hline $64 \mathrm{R}-1,123-125$ & 584.43 & F7 & 100 & 1.39 & 0.12 & 0.09 & 3.3 \\
\hline $64 R-2,92-94$ & 585.40 & F7 & 50 & 1.16 & 0.11 & 0.10 & 4.0 \\
\hline $64 R-2,109-111$ & 585.59 & F7 & 100 & (a) & (a) & (a) & (a) \\
\hline $64 R-3,114-116$ & 587.12 & F9 & 100 & 1.32 & 0.11 & 0.08 & 3.3 \\
\hline $65 \mathrm{R}-1,38-40$ & 593.08 & F9 & 10 & (a) & (a) & (a) & (a) \\
\hline $65 \mathrm{R}-1,62-64$ & 593.32 & F10 & 50 & 1.17 & 0.11 & 0.09 & 3.4 \\
\hline $65 \mathrm{R}-3,24-26$ & 595.45 & F10 & 200 & 1.35 & 0.11 & 0.08 & 3.3 \\
\hline $65 R-5,96-98$ & 598.98 & F10 & 50 & 0.95 & 0.09 & 0.09 & 3.3 \\
\hline $66 \mathrm{R}-2,110-112$ & 604.69 & F11 & 150 & 0.83 & 0.07 & 0.08 & 3.0 \\
\hline $66 \mathrm{R}-4,123-125$ & 607.40 & F11 & (a) & 1.26 & 0.12 & 0.09 & 3.7 \\
\hline $67 \mathrm{R}-1,87-89$ & 612.40 & F12 & (a) & 1.16 & 0.14 & 0.12 & 4.2 \\
\hline $67 \mathrm{R}-3,29-31$ & 614.74 & F14 & 50 & 1.43 & 0.12 & 0.08 & 3.4 \\
\hline $67 R-3,80-82$ & 615.25 & F14 & 10 & 1.11 & 0.16 & 0.14 & 6.2 \\
\hline $67 R-4,122-124$ & 617.16 & F15 & 40 & 1.21 & 0.13 & 0.11 & 4.1 \\
\hline $67 R-5,37-39$ & 617.78 & F15 & 15 & 0.99 & 0.10 & 0.11 & 3.8 \\
\hline $68 \mathrm{R}-2,123-125$ & 623.52 & F16 & 50 & 2.58 & 0.21 & 0.08 & 5.2 \\
\hline $68 \mathrm{R}-3,72-74$ & 624.50 & F17 & 35 & 1.05 & 0.11 & 0.10 & 4.5 \\
\hline $68 R-4,33-35$ & 625.43 & F17 & 35 & 0.99 & 0.10 & 0.10 & 3.8 \\
\hline $69 \mathrm{R}-1,23-25$ & 630.43 & F17 & 50 & (a) & (a) & (a) & (a) \\
\hline $69 R-2,109-111$ & 632.60 & F17 & (a) & 0.86 & 0.07 & 0.08 & 3.0 \\
\hline $69 R-4,58-60$ & 634.78 & F17 & 50 & 1.18 & 0.16 & 0.13 & 8.7 \\
\hline $69 R-5,27-29$ & 635.87 & F17 & 50 & (a) & (a) & (a) & (a) \\
\hline $69 \mathrm{R}-5,115-117$ & 636.75 & F17 & 50 & (a) & (a) & (a) & (a) \\
\hline $69 \mathrm{R}-6,17-19$ & 637.12 & F18 & 25 & 1.34 & 0.13 & 0.10 & 4.2 \\
\hline $70 \mathrm{R}-1,74-76$ & 640.14 & F18 & (a) & 1.05 & 0.08 & 0.07 & 2.8 \\
\hline $70 R-2,67-69$ & 641.57 & F19 & 10 & 0.90 & 0.14 & 0.16 & 6.7 \\
\hline $71 \mathrm{R}-1,89-91$ & 649.49 & $\mathrm{~F} 20$ & 75 & 1.08 & 0.09 & 0.08 & 3.1 \\
\hline $71 \mathrm{R}-3,121-123$ & 652.76 & $\mathrm{~F} 23$ & 10 & 0.97 & 0.13 & 0.13 & 7.1 \\
\hline $72 \mathrm{R}-1,91-93$ & 658.91 & F24 & 15 & 1.11 & 0.10 & 0.09 & 4.1 \\
\hline $72 R-2,72-74$ & 660.14 & $\mathrm{~F} 24$ & 25 & 1.05 & 0.12 & 0.11 & 4.5 \\
\hline $72 R-3,12-14$ & 661.04 & F25 & 20 & 1.04 & 0.14 & 0.13 & 5.9 \\
\hline $72 R-4,50-52$ & 662.75 & F25 & 50 & 1.00 & 0.11 & 0.11 & 4.6 \\
\hline $72 R-4,132-134$ & 663.57 & F 25 & 50 & (a) & (a) & (a) & (a) \\
\hline $73 R-1,121-123$ & 668.81 & $\mathrm{~F} 27$ & 15 & 1.02 & 0.10 & 0.10 & 3.8 \\
\hline $73 R-3,102-104$ & 671.52 & F29 & 15 & 1.46 & 0.13 & 0.09 & 4.5 \\
\hline $73 R-3,123-125$ & 671.76 & F29 & 15 & 1.20 & 0.12 & 0.10 & 4.2 \\
\hline
\end{tabular}

Note: (a) indicates that no measurement was made.

a Sample from Hole $756 \mathrm{C}$.

Aside from this sample, all compositions were in excess of $x=$ 0.5 , with most above $x=0.65$ (arithmetic mean, 0.69 , excluding the 0.24 value). Ilmenite values are generally between $x=0.90$ and $x=1.00$.

Site 757 had a much narrower distribution with virtually all $x$-values between 0.7 and 0.90 (mean, 0.77 ). The $x=0.02$ value was apparently made on a secondary hematite grain and hence not representative of primary composition. Some ilmenite values for this site exceed $x=1.00$, the maximum for stoichiometric ilmenite. The reason for this phenomenon is not clear, but may be related to alteration.

Site 758 had a very broad distribution, but almost all of the measurements with $x<0.6$ came from Sample 121-758A-56R-1, $69-71 \mathrm{~cm}$, which had an average composition of $x=0.24$. Excluding this sample, the average composition of the remaining five samples was 0.65 . No ilmenite was measured. 
Table 4. Microprobe data from Sites 756, 757, and 758.

\begin{tabular}{|c|c|c|c|c|c|c|c|}
\hline $\begin{array}{l}\text { Core, section, } \\
\text { interval }(\mathrm{cm})\end{array}$ & $\begin{array}{c}\text { Spot } \\
\text { number }\end{array}$ & $\mathrm{FeO}$ & $\mathrm{TiO}_{2}$ & $\mathrm{MnO}$ & $\mathrm{AlO}_{1.5}$ & $\mathrm{MgO}$ & $x$-value \\
\hline \multicolumn{8}{|l|}{$121-756 \mathrm{C}$ - } \\
\hline \multirow[t]{10}{*}{$10 \mathrm{~N}-1,27-29$} & 1 & 74.38 & 19.78 & 1.01 & 4.24 & 0.50 & 0.63 \\
\hline & $b_{2 a}$ & 50.26 & 43.17 & 0.79 & 0.36 & 5.39 & 0.92 \\
\hline & $a_{2 b}$ & 75.92 & 14.01 & 0.48 & 6.26 & 3.17 & 0.47 \\
\hline & $b_{3}$ & 46.77 & 45.76 & 0.86 & 0.21 & 6.39 & 0.99 \\
\hline & 4 & 74.95 & 19.21 & 0.40 & 4.22 & 1.12 & 0.61 \\
\hline & 5 & 74.58 & 20.27 & 0.63 & 3.72 & 0.65 & 0.64 \\
\hline & 6 & 71.67 & 19.14 & 0.55 & 4.26 & 3.74 & 0.63 \\
\hline & 7 & 72.43 & 21.91 & 0.84 & 4.42 & 0.27 & 0.70 \\
\hline & 8 & 69.71 & 20.63 & 0.63 & 4.62 & 4.19 & 0.69 \\
\hline & 9 & 74.05 & 15.57 & 0.44 & 6.52 & 3.17 & 0.52 \\
\hline \multicolumn{8}{|l|}{ 121-756D- } \\
\hline \multirow[t]{7}{*}{$6 \mathrm{R}-2,5-7$} & $c_{1}$ & 72.21 & 22.74 & (a) & 5.04 & (a) & 0.72 \\
\hline & $c_{2}$ & 70.03 & 23.09 & (a) & 6.89 & (a) & 0.74 \\
\hline & 3 & 68.46 & 26.31 & (a) & 5.23 & (a) & 0.83 \\
\hline & $c_{4}$ & 67.66 & 26.56 & (a) & 5.77 & (a) & 0.85 \\
\hline & $c_{5}$ & 69.85 & 25.01 & (a) & 5.13 & (a) & 0.79 \\
\hline & 6 & 69.03 & 25.85 & (a) & 5.12 & (a) & 0.82 \\
\hline & $c_{7}$ & 69.87 & 26.66 & (a) & 3.47 & (a) & 0.83 \\
\hline \multirow[t]{6}{*}{$7 R-1,41-43$} & 1 & 83.92 & 7.24 & 0.77 & 1.73 & 6.18 & 0.24 \\
\hline & $a_{2}$ & 81.57 & 7.96 & 0.29 & 8.77 & 1.32 & 0.27 \\
\hline & $a_{3}$ & 82.84 & 6.31 & 0.14 & 9.24 & 1.19 & 0.21 \\
\hline & $a_{4}$ & 76.73 & 12.64 & 0.22 & 7.67 & 2.65 & 0.42 \\
\hline & $a_{5}$ & 91.69 & 2.25 & 0.12 & 4.51 & 0.22 & 0.07 \\
\hline & $a_{6}$ & 83.78 & 6.50 & 0.13 & 8.40 & 1.14 & 0.22 \\
\hline \multirow[t]{14}{*}{$7 R-3,47-49$} & $b_{1}$ & 50.69 & 48.97 & (a) & 0.34 & (a) & 0.98 \\
\hline & 2 & 71.26 & 24.99 & (a) & 3.75 & (a) & 0.78 \\
\hline & 3 & 71.47 & 23.94 & (a) & 4.59 & (a) & 0.75 \\
\hline & 4 & 69.59 & 25.03 & (a) & 5.38 & (a) & 0.79 \\
\hline & 5 & 69.70 & 25.08 & (a) & 5.22 & (a) & 0.79 \\
\hline & 6 & 70.27 & 25.32 & (a) & 4.42 & (a) & 0.79 \\
\hline & $b_{7}^{0}$ & 50.80 & 48.76 & (a) & 0.44 & (a) & 0.98 \\
\hline & $8 \mathrm{a}$ & 72.23 & 21.91 & (a) & 5.86 & (a) & 0.70 \\
\hline & $8 b$ & 72.37 & 21.74 & (a) & 5.89 & (a) & 0.69 \\
\hline & ${ }^{8} 8 \mathrm{c}$ & 71.51 & 23.53 & (a) & 4.97 & (a) & 0.74 \\
\hline & $9 a$ & 72.28 & 22.53 & (a) & 5.19 & (a) & 0.71 \\
\hline & ${ }^{c} 9 \mathrm{~b}$ & 69.83 & 25.91 & (a) & 4.26 & (a) & 0.81 \\
\hline & $10 \mathrm{a}$ & 71.59 & 22.89 & (a) & 5.52 & (a) & 0.73 \\
\hline & $10 \mathrm{~b}$ & 71.11 & 23.51 & (a) & 5.37 & (a) & 0.75 \\
\hline \multirow[t]{8}{*}{$8 \mathrm{R}-1,16-18$} & $c_{1}$ & 83.43 & 12.82 & (a) & 3.75 & (a) & 0.40 \\
\hline & 2 & 67.69 & 28.14 & (a) & 4.17 & (a) & 0.88 \\
\hline & $c_{3}$ & 70.08 & 24.60 & (a) & 5.32 & (a) & 0.78 \\
\hline & $c_{4}$ & 68.64 & 25.26 & (a) & 6.09 & (a) & 0.81 \\
\hline & $c_{5}$ & 71.53 & 22.57 & (a) & 5.91 & (a) & 0.72 \\
\hline & $c_{6}$ & 69.40 & 25.82 & (a) & 4.78 & (a) & 0.81 \\
\hline & $c_{7}$ & 69.11 & 24.10 & (a) & 6.79 & (a) & 0.78 \\
\hline & $c_{8}$ & 72.71 & 21.42 & (a) & 5.88 & (a) & 0.68 \\
\hline \multirow[t]{9}{*}{$9 \mathrm{R}-2,32-34$} & $b_{1}$ & 52.09 & 47.51 & (a) & 0.40 & (a) & 0.95 \\
\hline & $b_{2}$ & 52.93 & 46.69 & (a) & 0.38 & (a) & 0.94 \\
\hline & $b_{3}$ & 52.62 & 47.01 & (a) & 0.37 & (a) & 0.94 \\
\hline & $a_{4}$ & 87.80 & 5.43 & (a) & 6.76 & (a) & 0.17 \\
\hline & 5 & 76.04 & 18.02 & (a) & 5.94 & (a) & 0.57 \\
\hline & ${ }^{2} 6 a$ & 94.61 & 0.99 & (a) & 4.40 & (a) & 0.03 \\
\hline & $c_{6 b}$ & 79.14 & 17.17 & (a) & 3.69 & (a) & 0.53 \\
\hline & $a_{7}$ & 80.69 & 14.99 & (a) & 4.32 & (a) & 0.47 \\
\hline & $a_{8}$ & 78.43 & 17.48 & (a) & 4.09 & (a) & 0.55 \\
\hline \multirow[t]{9}{*}{$12 \mathrm{R}-3,25-27$} & $c_{1}$ & 71.71 & 23.88 & (a) & 4.41 & (a) & 0.75 \\
\hline & $c_{2}$ & 75.64 & 20.61 & (a) & 3.74 & (a) & 0.64 \\
\hline & $\mathrm{a}, c_{3}$ & 78.60 & 17.08 & (a) & 4.32 & (a) & 0.54 \\
\hline & ${ }^{a} 4 a$ & 74.57 & 20.84 & (a) & 4.59 & (a) & 0.66 \\
\hline & $c_{4 b}$ & 73.43 & 22.28 & (a) & 4.28 & (a) & 0.70 \\
\hline & $c_{5}$ & 72.35 & 22.72 & (a) & 4.93 & (a) & 0.72 \\
\hline & $c_{6}$ & 72.24 & 23.58 & (a) & 4.18 & (a) & 0.74 \\
\hline & $c_{7}$ & 73.49 & 22.59 & (a) & 3.92 & (a) & 0.71 \\
\hline & 8 & 74.53 & 21.81 & (a) & 3.66 & (a) & 0.68 \\
\hline
\end{tabular}


Table 4 (continued).

\begin{tabular}{|c|c|c|c|c|c|c|c|}
\hline $\begin{array}{l}\text { Core, section, } \\
\text { interval }(\mathrm{cm})\end{array}$ & $\begin{array}{c}\text { Spot } \\
\text { number }\end{array}$ & $\mathrm{FeO}$ & $\mathrm{TiO}_{2}$ & $\mathrm{MnO}$ & $\mathrm{AlO}_{1.5}$ & $\mathrm{MgO}$ & $x$-value \\
\hline \multicolumn{8}{|l|}{$121-757 \mathrm{C}$ - } \\
\hline \multirow[t]{6}{*}{$8 \mathrm{R}-1,122-124$} & 1 & 74.38 & 17.72 & (a) & 7.89 & (a) & 0.58 \\
\hline & 2 & 69.10 & 25.05 & (a) & 5.84 & (a) & 0.80 \\
\hline & 3 & 83.71 & 14.02 & (a) & 1.46 & (a) & 0.45 \\
\hline & 4 & 71.99 & 22.47 & (a) & 5.54 & (a) & 0.71 \\
\hline & 5 & 71.47 & 21.99 & (a) & 6.54 & (a) & 0.71 \\
\hline & 6 & 71.04 & 22.10 & (a) & 6.86 & (a) & 0.71 \\
\hline \multirow[t]{8}{*}{ 9R-1, 26-28 } & $c_{1}$ & 75.15 & 22.54 & (a) & 2.31 & (a) & 0.69 \\
\hline & $c_{2}$ & 68.99 & 26.27 & (a) & 4.74 & (a) & 0.83 \\
\hline & $c_{3}$ & 71.89 & 23.96 & (a) & 4.15 & (a) & 0.75 \\
\hline & $c_{4}$ & 69.91 & 26.99 & (a) & 3.11 & (a) & 0.84 \\
\hline & $c_{5}$ & 75.91 & 21.78 & (a) & 2.31 & (a) & 0.67 \\
\hline & $c_{6}$ & 71.45 & 26.04 & (a) & 2.51 & (a) & 0.80 \\
\hline & $c_{7}$ & 71.68 & 26.18 & (a) & 2.15 & (a) & 0.80 \\
\hline & $c_{8}$ & 72.87 & 25.46 & (a) & 1.67 & (a) & 0.78 \\
\hline \multirow[t]{9}{*}{$10 \mathrm{R}-3,77-79$} & $1 \mathrm{a}$ & 63.40 & 23.38 & 0.56 & 9.46 & 1.34 & 0.81 \\
\hline & lb & 66.39 & 22.34 & 0.54 & 8.51 & 1.24 & 0.76 \\
\hline & 2 & 64.71 & 28.93 & 0.87 & 4.61 & 0.49 & 0.93 \\
\hline & $b_{3}$ & 42.13 & 54.69 & 1.35 & 1.14 & 0.33 & 1.13 \\
\hline & $b_{4}$ & 44.39 & 51.52 & 1.26 & 1.74 & 0.41 & 1.07 \\
\hline & 5 & 64.74 & 27.32 & 1.05 & 6.15 & 0.26 & 0.89 \\
\hline & 6 & 74.72 & 0.43 & 0.22 & 8.69 & 3.21 & 0.02 \\
\hline & 7 & 67.58 & 24.18 & 1.22 & 6.05 & 0.36 & 0.79 \\
\hline & 8 & 67.29 & 20.81 & 0.40 & 9.53 & 1.64 & 0.71 \\
\hline \multirow[t]{10}{*}{$12 \mathrm{R}-1,53-55$} & $c_{1}$ & 73.77 & 23.95 & (a) & 2.28 & (a) & 0.74 \\
\hline & $c_{2}$ & 70.32 & 26.08 & (a) & 3.60 & (a) & 0.81 \\
\hline & $c_{3}$ & 68.33 & 28.22 & (a) & 3.44 & (a) & 0.88 \\
\hline & $c_{4}$ & 70.59 & 26.27 & (a) & 3.13 & (a) & 0.81 \\
\hline & $c_{5}$ & 75.10 & 22.32 & (a) & 2.57 & (a) & 0.69 \\
\hline & $b, c_{6}$ & 48.54 & 51.16 & (a) & 0.30 & (a) & 1.03 \\
\hline & $c_{7}$ & 71.20 & 24.42 & (a) & 4.38 & (a) & 0.77 \\
\hline & $c_{8}^{\prime}$ & 68.36 & 28.59 & (a) & 3.05 & (a) & 0.88 \\
\hline & $c_{9}$ & 73.93 & 22.15 & (a) & 3.91 & (a) & 0.69 \\
\hline & $c_{10}$ & 70.61 & 26.07 & (a) & 3.32 & (a) & 0.81 \\
\hline \multirow[t]{8}{*}{$12 \mathrm{R}-1,92-94$} & 1 & 70.20 & 26.56 & (a) & 3.24 & (a) & 0.82 \\
\hline & 2 & 71.14 & 25.80 & (a) & 3.06 & (a) & 0.80 \\
\hline & 3 & 71.44 & 25.88 & (a) & 2.67 & (a) & 0.80 \\
\hline & 4 & 70.56 & 26.96 & (a) & 2.48 & (a) & 0.83 \\
\hline & 5 & 69.52 & 27.57 & (a) & 2.91 & (a) & 0.85 \\
\hline & 6 & 70.53 & 26.85 & (a) & 2.62 & (a) & 0.83 \\
\hline & 7 & 69.30 & 26.70 & (a) & 4.00 & (a) & 0.83 \\
\hline & 8 & 73.88 & 24.22 & (a) & 1.90 & (a) & 0.74 \\
\hline
\end{tabular}

\section{DISCUSSION}

The primary oxide composition of these rocks, especially at Site 757, was generally higher than that of most seafloor basalts, which have compositions of about $x=0.6$ (e.g., Johnson, 1979). Similar compositions are found for the Nintoku and Suiko seamounts of the Emperor chain (Kono et al., 1980). Other seamounts generally have lower $x$-values (e.g., Jasper Seamount, $x=0.46-0.7$, Gee et al., 1988 ; La Palma Island, $x \approx 0.4$, Gee et al., 1989). Submarine volcanic samples from La Palma Island contain skeletal grains that span nearly the entire solid-solution series $(x=0.05-0.85$; J. Gee, unpubl. data).

Stoichiometric oxides with $x$ above 0.8 have Curie points below room temperature and are thus nonmagnetic (e.g., Stacey and Banerjee, 1974). The addition of $\mathrm{Al}$ reduces the Curie temperature further (approximately $50^{\circ} \mathrm{C}$ for $10 \% \mathrm{Al}$; Ozdemir and O'Reilly, 1981). Thus, even compositions below $x=0.8$ may be sufficiently thermally unstable that they will retain no long-term remanence. The fact that these rocks do have NRMs that are apparently tens of millions of years old must, in many cases, be a result of alteration.

Oxidation exsolution, quite apparent in many samples, produces a low-Ti, high-Curie temperature spinel phase that can be quite stable. Stability is actually further enhanced by the presence of trellis lamellae, which subdivide the original grain. Many samples with optically homogeneous grains also carry stable remanence and have a generally similar magnetic character. There are two basic hypotheses that can explain this phenomenon. One is that these grains are also exsolved, but on a scale too fine for optical microscopy (e.g., Evans and Wayman, 1974). A similar situation occurs in the transition zone and upper dike complex of Hole 504B (Smith and Banerjee, 1986). This phenomenon was also reported from Bermuda Seamount (Rice et al., 1980). The other possibility is that the titanomagnetites are still single phase but have undergone low-temperature alteration. The cation-deficient spinels produced by this form of alteration can have Curie temperatures as much as $200^{\circ}-300^{\circ} \mathrm{C}$ higher than stoichiometric oxides of the same composition (e.g., Readman and O'Reilly, 1972). Low-temperature alteration is certainly present, as indicated by the presence of shrinkage cracks in many samples and suggested by the low totals of the raw electron microprobe data. The intensity of alteration is least at Site 756 and greatest at Site 758. Although NRM would be expected to decrease with increasing alteration, the high NRM values of Site 758 can be accounted for by larger titanomagnetite concentrations, as indicated by the $\mathrm{J}_{\mathrm{s}}$ measurements. This pattern is consistent with a slow process, with intensity of alteration primarily controlled simply by the age of the rock. Studies of this type of alteration in seafloor basalts suggest that although changes in NRM magnitude may take place, directional changes are probably negligible (Soroka and BeskeDiehl, 1984; Beske-Diehl and Soroka, 1984). The major difference here is that some of the samples may have been initially 
Table 4 (continued).

\begin{tabular}{|c|c|c|c|c|c|c|c|}
\hline $\begin{array}{l}\text { Core, section, } \\
\text { interval }(\mathrm{cm})\end{array}$ & $\begin{array}{c}\text { Spot } \\
\text { number }\end{array}$ & $\mathrm{FeO}$ & $\mathrm{TiO}_{2}$ & $\mathrm{MnO}$ & $\mathrm{AlO}_{1.5}$ & $\mathrm{MgO}$ & $x$-value \\
\hline \multicolumn{8}{|l|}{$121-758 \mathrm{~A}-$} \\
\hline \multirow[t]{8}{*}{$56 \mathrm{R}-1,69-71$} & 1 & 83.81 & 14.38 & (a) & 1.81 & (a) & 0.44 \\
\hline & 2 & 88.72 & 10.19 & (a) & 1.09 & (a) & 0.31 \\
\hline & 3 & 90.06 & 6.88 & (a) & 3.06 & (a) & 0.21 \\
\hline & 4 & 91.57 & 5.29 & (a) & 3.14 & (a) & 0.16 \\
\hline & 5 & 90.79 & 5.73 & (a) & 3.47 & (a) & 0.18 \\
\hline & 6 & 88.92 & 5.75 & (a) & 5.34 & (a) & 0.18 \\
\hline & 7 & 87.31 & 7.16 & (a) & 5.53 & (a) & 0.23 \\
\hline & 8 & 87.91 & 7.27 & (a) & 4.82 & (a) & 0.23 \\
\hline \multirow[t]{8}{*}{$61 \mathrm{R}-7,11-13$} & 1 & 74.15 & 21.05 & (a) & 4.79 & (a) & 0.66 \\
\hline & 2 & 72.41 & 19.86 & (a) & 7.73 & (a) & 0.65 \\
\hline & 3 & 73.91 & 21.56 & (a) & 4.52 & (a) & 0.68 \\
\hline & 4 & 75.58 & 19.62 & (a) & 4.79 & (a) & 0.62 \\
\hline & 5 & 72.91 & 20.40 & (a) & 6.69 & (a) & 0.66 \\
\hline & 6 & 72.44 & 20.79 & (a) & 6.77 & (a) & 0.67 \\
\hline & 7 & 72.91 & 21.85 & (a) & 5.24 & (a) & 0.69 \\
\hline & 8 & 72.02 & 21.28 & (a) & 6.70 & (a) & 0.68 \\
\hline \multirow[t]{9}{*}{$62 \mathrm{R}-2,125-127$} & 1 & 72.06 & 22.71 & (a) & 5.23 & (a) & 0.72 \\
\hline & 2 & 72.01 & 23.32 & (a) & 4.66 & (a) & 0.73 \\
\hline & 3 & 71.89 & 21.78 & (a) & 6.33 & (a) & 0.70 \\
\hline & 4 & 74.71 & 19.62 & (a) & 5.68 & (a) & 0.62 \\
\hline & 5 & 74.06 & 21.37 & (a) & 4.57 & (a) & 0.67 \\
\hline & 6 & 72.14 & 22.81 & (a) & 5.05 & (a) & 0.72 \\
\hline & 7 & 75.02 & 19.79 & (a) & 5.20 & (a) & 0.63 \\
\hline & 8 & 73.11 & 21.91 & (a) & 4.97 & (a) & 0.69 \\
\hline & 9 & 72.09 & 23.09 & (a) & 4.82 & (a) & 0.73 \\
\hline \multirow[t]{12}{*}{$69 \mathrm{R}-1,23-25$} & 1 & 71.92 & 18.86 & 0.0 & 8.02 & 1.04 & 0.62 \\
\hline & 2 & 72.47 & 20.14 & 0.0 & 6.31 & 0.95 & 0.65 \\
\hline & 3 & 71.56 & 19.82 & 0.0 & 7.37 & 1.07 & 0.65 \\
\hline & 4 & 75.78 & 16.95 & 0.0 & 5.89 & 0.92 & 0.55 \\
\hline & 5 & 73.37 & 20.09 & 0.0 & 5.81 & 0.55 & 0.64 \\
\hline & $6 a$ & 73.69 & 17.92 & 0.0 & 7.40 & 0.80 & 0.59 \\
\hline & $6 \mathrm{~b}$ & 73.06 & 20.49 & 0.0 & 5.63 & 0.52 & 0.66 \\
\hline & 7 & 72.29 & 22.19 & 0.0 & 5.05 & 0.31 & 0.70 \\
\hline & 8 & 72.63 & 20.96 & 0.0 & 5.48 & 0.77 & 0.67 \\
\hline & 9 & 74.31 & 20.68 & 0.0 & 4.17 & 0.72 & 0.65 \\
\hline & 10 & 73.99 & 20.48 & 0.0 & 4.55 & 0.86 & 0.65 \\
\hline & 11 & 73.09 & 20.89 & 0.0 & 5.39 & 0.46 & 0.67 \\
\hline \multirow[t]{11}{*}{$72 R-4,132-134$} & 1 & 71.84 & 21.50 & 0.0 & 6.43 & 0.02 & 0.69 \\
\hline & 2 & 71.70 & 19.48 & 0.0 & 8.39 & 0.17 & 0.64 \\
\hline & 3 & 70.37 & 21.30 & 0.0 & 7.37 & 0.30 & 0.70 \\
\hline & 4 & 72.10 & 21.50 & 0.0 & 6.19 & 0.00 & 0.69 \\
\hline & 5 & 74.54 & 17.77 & 0.0 & 7.04 & 0.39 & 0.58 \\
\hline & 6 & 71.64 & 20.95 & 0.0 & 7.14 & 0.04 & 0.68 \\
\hline & 7 & 70.03 & 19.50 & 0.0 & 8.24 & 0.78 & 0.65 \\
\hline & 8 & 76.36 & 17.10 & 0.0 & 5.97 & 0.35 & 0.55 \\
\hline & 9 & 71.31 & 23.40 & 0.0 & 5.10 & 0.00 & 0.74 \\
\hline & 10 & 74.37 & 19.84 & 0.0 & 5.32 & 0.26 & 0.63 \\
\hline & 11 & 70.47 & 23.94 & 0.0 & 5.38 & 0.00 & 0.76 \\
\hline \multirow[t]{8}{*}{$72 R-4,50-52$} & 1 & 73.03 & 19.68 & (a) & 7.29 & (a) & 0.64 \\
\hline & 2 & 71.44 & 20.83 & (a) & 7.73 & (a) & 0.68 \\
\hline & 3 & 73.36 & 18.96 & (a) & 7.67 & (a) & 0.62 \\
\hline & 4 & 76.10 & 16.10 & (a) & 7.81 & (a) & 0.52 \\
\hline & 5 & 73.32 & 19.82 & (a) & 6.85 & (a) & 0.64 \\
\hline & 6 & 72.70 & 19.73 & (a) & 7.57 & (a) & 0.64 \\
\hline & 7 & 77.63 & 16.30 & (a) & 6.07 & (a) & 0.52 \\
\hline & 8 & 72.88 & 20.04 & (a) & 7.08 & (a) & 0.65 \\
\hline
\end{tabular}

Note: Each spot number represents a different measurement; letters indicate different spots on the same grain. Spot size is $1 \mu \mathrm{m}$ (nominal) unless otherwise noted. Cation values are given in atomic percent. The $x$-value assumes stoichiometric titanomagnetite or hemoilmenite calculated from $\mathrm{Fe}$ and $\mathrm{Ti}$ only. (a) indicates that no measurement was made.

a Magnetite region in exsolved grain.

b Ilmenite grain.

${ }^{\mathrm{c}}$ Spot size $10 \mu \mathrm{m}$. 

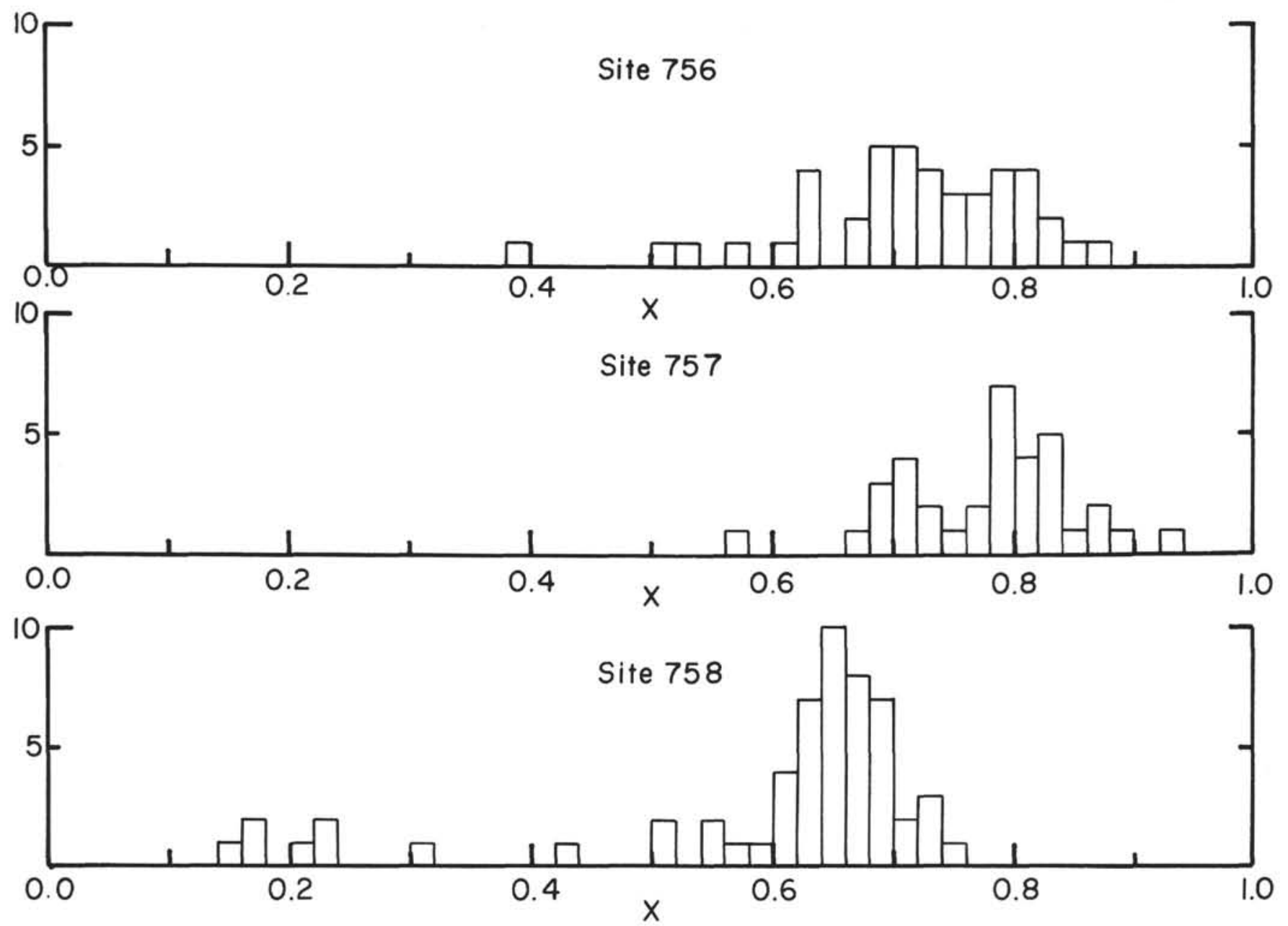

Figure 7. Histogram of electron microprobe data from Sites 756, 757, and 758. Individual spot measurements are included separately; spots on ilmenite grains and on spinel regions with exsolved grains are not included.

nonmagnetic. Several million years might be required before the Curie temperature is high enough to permit a stable remanence, resulting in an anomalously shallow inclination. Although inclination does tend to be somewhat shallow for these sites, there is no indication that the homogeneous samples are preferentially lower in inclination, suggesting that remanence is probably locked-in fairly rapidly.

Thermomagnetic analysis is generally necessary to determine whether low-temperature alteration is present. Some information can be extracted from thermal demagnetization data, although there is the potential for unrecognized alteration due to heating. The blocking temperature spectra, even for samples from Site 758, are commonly in excess of $500^{\circ} \mathrm{C}$ (Klootwijk et al., this volume). This is much higher than could be achieved by low-temperature oxidation and is consistent with suboptical exsolution. Resolution of this problem will have to await the thermomagnetic results.

It is not at all clear why some samples are exsolved and some not. As rocks cool, a constant oxygen fugacity will cause the stable composition of both the spinel and rhombohedral phases to become more Fe rich (e.g., Spencer and Lindsley, 1981). Thus, the presence or absence of lamellae should be largely a function of the cooling rate. The flows of Sites 756 and 757 were deposited subaerially (e.g., Peirce, Weissel, et al., 1989). They can be expected to have cooled relatively slowly, and they were also directly exposed to air, leading to the large proportion of exsolved samples observed.

The relatively rapid cooling of the submarine flows at Site 758 may, in general, account for the small number of exsolved samples, but there are some problems in detail. Flow Unit 758A-F2, in particular, is curious, as the interior of the flow, which would have the slowest cooling rate (as evidenced by the large grain size), also contains homogeneous grains with exsolved grains found near the flow margin. Even if the interior samples are exsolved microscopically, we still have the opposite of what is predicted by the conventional deuteric oxidation model. A similar pattern is seen in flow Unit 758A-F3. Homogeneous samples found at Sites 756 and 757 are also generally in the interior of the flow. The exception is flow Unit 757C-F19. There is no chill zone at the bottom of flow Unit 757C-F18, suggesting that perhaps it was deposited while Unit 757C-F19 was still at a high temperature. This pattern of oxidation suggests that the availability of oxygen at the margin of the flow may be more important than the cooling rate. Hydrothermal circulation may also be a factor.

In addition to alteration of the primary oxides, there is also evidence for the existence of secondary oxides, produced after deposition. Samples from both Sites 756 and 757 show a brown 
or reddish color, commonly attributed to the presence of hematite or iron oxyhydroxides, such as goethite. Their small size usually renders such "pigmentary" oxides difficult to detect optically. Many samples from these sites have observable secondary hematite, however, indicating that pigment oxides are probably present. Hematite and goethite both have high coercivities, and their presence may be at least partly responsible for the high MDFs observed for the two holes. The alteration that produced these secondary oxides is probably related to the fact that they were erupted subaerially and spent at least some time in this highly oxidizing environment. Site 757 , the more highly oxidized of the two sites, was also highly vesicular, which would have presumably enhanced groundwater flow through the flows and probably increased oxidation rates relative to those of Site 756 . If the alteration took place some millions of years after emplacement, some shallowing of inclination might result, although the lowsaturation magnetization of both hematite and goethite relative to titanomagnetite suggests that this magnetization would probably have only a small effect on the total remanence. As alteration seems to have taken place before or shortly after submersion, it seems quite unlikely that secondary minerals are responsible for the very shallow magnetizations seen at Site 757 . No secondary oxides were observed for Site 758. These rocks were deposited in deep water and apparently have had relatively little exposure to oxygen.

Oxide morphology is another puzzling matter. Sites 756 and 757 are subaerial flows, presumably deposited under similar conditions. Yet, the oxides of Site 756 are generally solid, subhedral to anhedral grains, whereas those of Site 757 are commonly euhedral, typically with extremely complex dendritic habits. A dendritic (or skeletal) habit is commonly associated with rapid cooling, which explains its presence in many seafloor basalts, especially near the margins of flows. Experimental work on the relationship between oxide habit and cooling rate is nonexistent, however, so any conclusions are speculative. Habits similar to those of seafloor basalts are seen in many Site 758 samples. That such rocks rarely contain the complex structures seen at Site 757 is probably due to the fact that the lava quenches to glass relatively rapidly, effectively stopping crystal growth. Perhaps Site 757 had a nearly optimal cooling rate, fast enough to favor dendritic crystal growth but slow enough for large crystals to form. The question is why no such crystals formed in the Site 756 rocks. The high degree of vesicularity of the Site 757 samples may be due to an abundance of volatile phases, which could, in turn, have affected oxide morphology, perhaps by a reduction in melt viscosity. An alternative explanation is that the lower melt density that resulted from unusually high $\mathrm{Al}_{2} \mathrm{O}_{3}$ concentrations (Frey et al., this volume) favored dendrites.

Another puzzle is the presence of ilmenite trellis lamellae in dendritic grains. As discussed previously, the development of trellis lamellae is commonly thought to require slow cooling, contrary to the conditions necessary for the formation of dendrites. This lends some support to the hypothesis that the critical factor in the formation of exsolution lamellae in these rocks is the availability of an external source of oxygen. An alternative is that the rocks were held at a temperature below the solidus but sufficiently high for exsolution to occur. The mechanisms by which such a scenario could occur (e.g., reheating by subsequent flows) cannot be ruled out, but are generally somewhat contrived.

\section{CONCLUSIONS}

An important goal of this work was to address the suitability of these rocks as a source for a magnetic anomaly. There are several factors that are necessary for a unit to contribute appre- ciably to anomalies. The most obvious is that the NRM must be sufficiently large (we assume here that only NRM-dominated anomalies are of interest). The magnitude necessary for anomaly production is a function of the depth and geometry of the anomaly-producing feature as well as the thickness of the unit in question. The induced moment in the Earth's magnetic field must be reasonably small or the portion of the anomaly due to the NRM is difficult to determine. For practical purposes, this is equivalent to requiring that $\mathrm{Q}$ be at least not much less than 1.0. Viscous remanence must also be small. The VRM acquired since the last reversal is, in effect, an induced remanence, but susceptibility measurements do not include viscous contributions (with a time constant of at least more than a fraction of a second). Finally, for the anomaly to be useful, the NRM must date from the time of emplacement (or at least be dateable). A paleomagnetic pole is of limited use if it cannot be dated.

The Site 756 rocks have only moderate NRM magnitudes relative to other comparable units (Table 2). The Koenigsberger ratios are also somewhat low, but still indicate an NRM-dominated magnetization. Analysis of vector demagnetization shows minimal low-angle components, indicating relatively little VRM. A comparison of the average paleolatitude with that expected for the Kerguelen-Heard hot spot suggests that the stable magnetic vector derives from or near the time of emplacement. That they are somewhat shallow compared to the expected Kerguelen-Heard latitude can be explained by a variety of mechanisms, most of which are discussed in Klootwijk et al. (this volume). Low-temperature alteration is not, however, a likely candidate because most of the rocks examined were exsolved and their magnetization directions would not be significantly affected by this process. It is difficult to assess how typical these rocks are of deeper units, but there is no obvious trend with depth, suggesting that extension of these results to moderate depths is at least plausible.

The Site 757 rocks are relatively weakly magnetized although the magnetization is very stable. The susceptibility is relatively large, yielding low Q values. This is somewhat surprising, as high MDFs are usually associated with low $\chi_{0}$ and high $Q$ values. One possible explanation is that much of the NRM is chemical in origin, which tends to produce a smaller remanence than a comparable thermal remanence (TRM).

It is not clear exactly when the magnetization was acquired. All but the lowest units had very shallow inclinations. It is possible that these flows were emplaced rapidly at a time when secular variation had reduced the inclination to $20^{\circ}$, although modern secular variation does not show such large departures from axial dipole values. An alternative, albeit contrived, is that the flows occurred during a geomagnetic excursion. It is difficult to independently establish whether such an excursion took place at the appropriate time. Although alteration combined with northward translation could, in principle, produce such low inclinations, we see no plausible way that it could be responsible for the inclinations observed at Site 757. Klootwijk et al. (this volume) suggested tectonic rotation as an explanation, which, although ad hoc, seems most plausible. It is not at all clear how representative these rocks are of deeper units. The low inclinations of the upper units change abruptly to high values near the bottom of the hole. Average $J_{\mathrm{S}}$ and NRM values differ by nearly a factor of 2 between these two subsections. We simply cannot say at this time which set of samples (if either) is truly representative.

The highest NRMs were found for the submarine flows recovered from Site 758 , although they are still low compared with those of other seamounts (Table 2). Their suitability as an anomaly source is moderated by relatively high $\chi_{0}$ and low $Q$ values. In addition, the analysis of demagnetization plots suggests that most of the samples appear to have appreciable VRM, ranging as 
high as $50 \%$ but typically in the $10 \%$ range. The inclinations of viscous components are low, consistent with recent viscous acquisition at the site. It thus appears to be a significant part of the magnetic signature but substantially less than the stable remanence in the majority of samples. The average primary inclination appears to be stable and date from or near the time of deposition.

Given that a substantial portion of potential source material is as yet unsampled, any conclusions are, of necessity, tentative, if not speculative. The rocks of Sites 756 and 758 appear to preserve remanent inclinations close to those expected with sufficient magnetic intensity and stability to create an appreciable surface anomaly. If this is also true for the declinations and the remainder of the magnetic source (however deep it may extend) then inversion should yield a true paleopole. On the other hand, the majority of the samples studied from Site 757 differ from the expected inclination by $40^{\circ}$ or so. If these are in fact typical of the entire section, inversions would be badly in error. The low-inclination upper portion of the section, however, has relatively low NRM magnitudes. If the remainder of the magnetized portion of the seamount has the right inclination and NRM intensities similar to those of the other two sites (as suggested by the samples from near the bottom of the hole), the contribution of the upper part of the section may be negligible. Such a nonmagnetic top was in fact suggested on the basis of an anomaly inversion for a seamount in the Gulf of Guinea by Harrison (1971).

These results have some implications for other seamounts. The samples from Sites 756 and 757 are subaerial and presumably represent lavas erupted late in the history of the volcano(s). As the more highly altered of the two sites, the Site 757 samples perhaps represent a later stage that was erupted higher in the pile and thus spent a longer time altering in the oxygen-rich subaerial environment. It is possible, however, that much of the difference in alteration state is due to the fact that the Site 757 rocks were much more vesicular and presumably more permeable. The Site 758 rocks were erupted below sea level and are perhaps representative of deeper levels in the edifice, which never reached the surface. Putting these data together to form a (highly speculative) seamount model, we have a island that consists of perhaps a thousand or more meters of subaerial basalt, weakly magnetized at the top and moderately magnetized lower down with a high magnetic stability and Q. Below these units are more magnetic submarine basalts with a lower magnetic stability and Q. Some of the section may be tectonically disrupted. The deeper sources are not well constrained, but the results of Gee et al. (1989) suggest that the intrusives may contribute appreciably to the anomaly.

Alternate interpretations of the data are quite possible. In short, the picture is still murky and admits a wide variety of possible models, but we are beginning to get an understanding of at least the outer shell of these interesting and important features.

\section{ACKNOWLEDGMENTS}

I (GS) am indebted to Steven Lund for the loan of his Molspin magnetometer after my PAR spinner finally succumbed to the ravages of age. Shi-Wei Sun performed the majority of the magnetic measurements. J. M. Hall and an anonymous reviewer offered valuable criticism. This research was supported by USSAC.

\section{REFERENCES}

Ade-Hall, J. M., Palmer, H. C., and Hubbard, T. P., 1971. The magnetic and opaque petrological response of basalts to regional hydrothermal alteration. Geophys. J. R. Astron. Soc., 24:137-174.

Beske-Diehl, S. J., and Soroka, W. L., 1984. Magnetic properties of variably oxidized pillow basalt. Geophys. Res. Lett., 11:217-220.

Chen, C.-Y., and Frey, F. A., 1983. Origin of Hawaiian tholeiite and alkalic basalt. Nature, 302:785-789.
Day, R., Fuller, M. D., and Schmidt, V. A., 1976. Magnetic hysteresis properties of synthetic titanomagnetites. J. Geophys. Res., 81:873880.

Duncan, R. A., 1978. Geochronology of basalts from the Ninetyeast Ridge and continental dispersion in the eastern Indian Ocean. J. Volcanol. Geotherm. Res., 4:283-305.

Duncan, R. A., Backman, J., MacDonald, A. H., et al., 1989. Réunion hotspot activity through Tertiary time: initial results from the Ocean Drilling Program, Leg 115. J. Volcanol. Geotherm. Res., 36:193-198.

Evans, M. E., and Wayman, M. L., 1974. An investigation of the role of ultra-fine titanomagnetite intergrowths in paleomagnetism. Geophys. J. R. Astron. Soc., 36:1-10.

Flower, M.F.J., 1973. Evolution of basaltic and differentiated lavas from Anjouan, Comores Archipelago. Contrib. Mineral. Petrol., 38:227260.

Francheteau, J., Harrison, C.G.A., Sclater, J. G., and Richards, M. L., 1970. Magnetization of Pacific seamounts: a preliminary polar wander curve for the northeastern Pacific. J. Geophys. Res., 75:20352061.

Furuta, T., Tonouchi, S., and Nakada, M., 1980. Magnetic properties of pillow basalt from the Kinan seamount chain, the Shikoku Basin. $J$. Geomagn. Geoelectr., 32:567-573.

Gee, J., Staudigel, H., and Tauxe, L., 1989. Contribution of induced magnetization to the magnetization of seamounts. Nature, 342:170173.

Gee, J., Tauxe, L., Hildebrand, J. A., Staudigel, H., and Lonsdale, P., 1988. Non-uniform magnetization of Jasper Seamount. J. Geophys. Res., 93:12159-12175.

Gordon, R. G., and Cox, A., 1980. Calculating paleomagnetic poles for oceanic plates. Geophys. J. R. Astron. Soc., 63:629-640.

Haggerty, S. E., 1976. Opaque mineral oxides in terrestrial igneous rocks. In Rumble, D., III (Ed.), Oxide Minerals: Mineral. Soc. Am., Short Course Notes, 3:101-277.

Harrison, C.G.A., 1971. A seamount with a non-magnetic top. Geophysics, $36: 349-357$.

Harrison, C.G.A., Jarrard, R. D., Vacquier, V., and Larson, L., 1975. Paleomagnetism of Cretaceous Pacific seamounts. Geophys. J. R. Astron. Soc., 42:859-882.

Hildebrand, J. A., and Parker, R. L., 1987. Paleomagnetism of Cretaceous Pacific seamounts revisited. J. Geophys. Res., 92:12695-12712.

Johnson, H. P., 1979. Magnetization of the oceanic crust. Rev. Geophys. Space Phys., 17:215-226.

Johnson, H. P., and Hall, J. M., 1978. A detailed rock magnetic and opaque mineralogy study of the basalts from the Nazca plate. Geophys. J. R. Astron. Soc., 52:45-64.

Kono, M., 1980. Magnetic properties of DSDP Leg 55 basalts. In Jackson, E. D., Koizumi, I., et al., Init. Repts. DSDP, 55: Washington (U.S. Govt. Printing Office), 723-752.

Kono, M., Clague, D., and Larson, E. E., 1980. Fe-Ti oxide mineralogy of DSDP Leg 55 basalts. In Jackson, E. D., Koizumi, I., et al., Init. Repts. DSDP, 55: Washington (U.S. Govt. Printing Office), 639-652.

Marshall, M., 1978. The magnetic properties of some DSDP basalts from the North Pacific and inferences for Pacific plate tectonics. J. Geophys. Res., 83:289-308.

McFadden, P. L., and Reid, A. B., 1982. Analysis of paleomagnetic inclination data. Geophys. J. R. Astron. Soc., 69:307-319.

Merrill, R. T., and Burns, R. E., 1972. A detailed magnetic study of Cobb Seamount. Earth Planet. Sci. Lett., 14:413-418.

Merrill, R. T., and McElhinny, M. W., 1983. The Earth's Magnetic Field: London (Academic Press).

Ozdemir, O., and O'Reilly, W., 1981. Laboratory synthesis of aluminumsubstituted titanomaghemites and their characteristic properties. $J$. Geophys., 49:93-100.

Parker, R. L., Shure, L., and Hildebrand, J. A., 1987. The application of inverse theory to seamount magnetism. Rev. Geophys., 25:17-40.

Peirce, J., Weissel, J., et al., 1989. Proc. ODP, Init. Repts., 121: College Station, TX (Ocean Drilling Program).

Readman, P. W., and O'Reilly, W. O., 1972. Magnetic properties of oxidized (cation-deficient) titanomagnetites. J. Geomagn. Geoelectr., 24:69-90.

Rice, P. D., Hall, J. M., and Opdyke, N. D., 1980. A paleomagnetic study of the Bermuda Seamount. Can. J. Earth Sci., 17:232-243. 
Sager, W. W., Davis, G. T., Keating, B. H., and Philpotts, J. A., 1982. A geophysical study of Nagata Seamount, northern Line Islands. $J$. Geomagn. Geoelectr., 34:283-305.

Schmincke, H.-U., 1976. The geology of the Canary Islands. In Kunkel, G. (Ed.), Biogeography and Ecology in the Canary Islands: The Hague (Junk Publishers).

Smith, G. M., and Banerjee, S. K., 1986. The magnetic structure of the upper kilometer of the marine crust at Deep Sea Drilling Project Hole 504B, eastern Pacific Ocean. J. Geophys. Res., 91:10337-10354.

Soroka, W., and Beske-Diehl, S., 1984. Variation of magnetic directions within pillow basalts. Earth Planet. Sci. Lett., 69:215-223.

Spencer, K. J., and Lindsley, D. H., 1981. A solution model for coexisting iron titanium oxides. Am. Mineral., 66:1189-1201.

Stacey, F., and Banerjee, S. K., 1974. The Physical Principles of Rock Magnetism: Amsterdam (Elsevier).

Talwani, M., 1965. Computation with help of a digital computer of magnetic anomalies caused by bodies of arbitrary shape. Geophysics, 30:797-817.
Tucker, P., and O'Reilly, W. O., 1980. The laboratory simulation of deuteric oxidation of titanomagnetites: effect on magnetic properties and stability of thermoremanence. Phys. Earth Planet. Inter., 133.

Vacquier, V., 1962. A machine method for computing the magnetization of a uniformly magnetized body from its shape and a magnetic survey. In Benedum Earth Magnetism Symposium: Pittsburgh (Univ. of Pittsburgh Press), 123-137.

Worm, H.-U., and Banerjee, S. K., 1984. Aqueous low temperature oxidation of titanomagnetite. Geophys. Res. Lett., 11:169-172.

Date of initial receipt: 30 April 1990

Date of acceptance: 7 November 1990

Ms 121B-154 


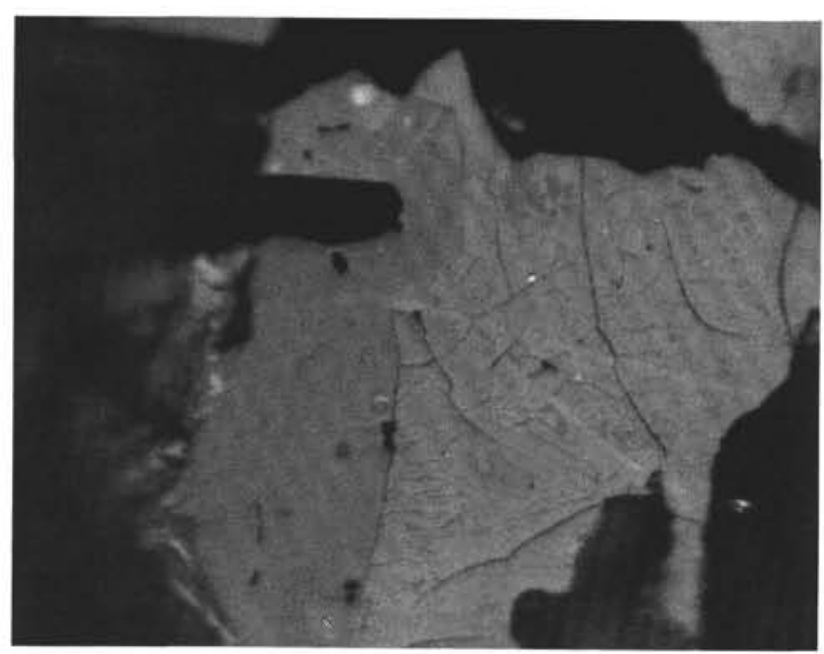

1

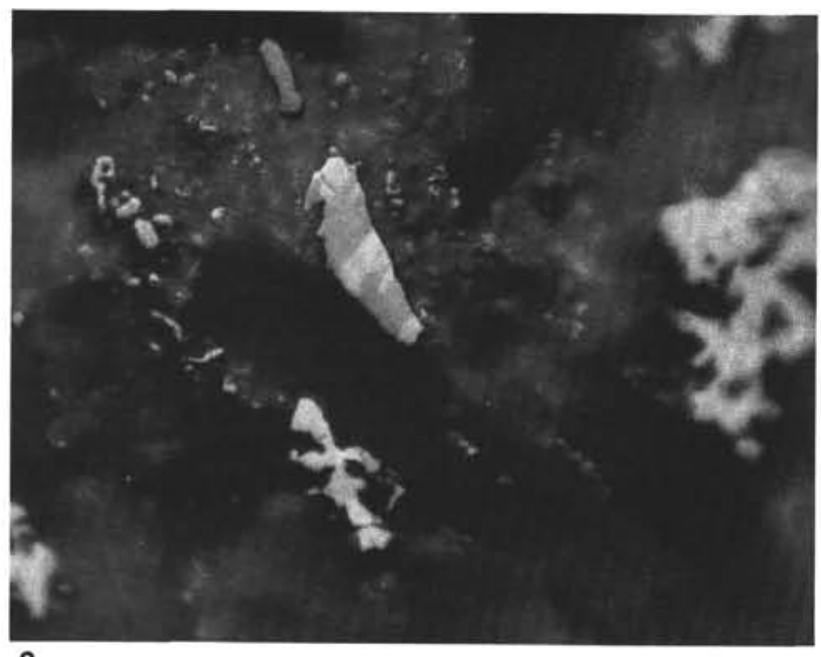

3

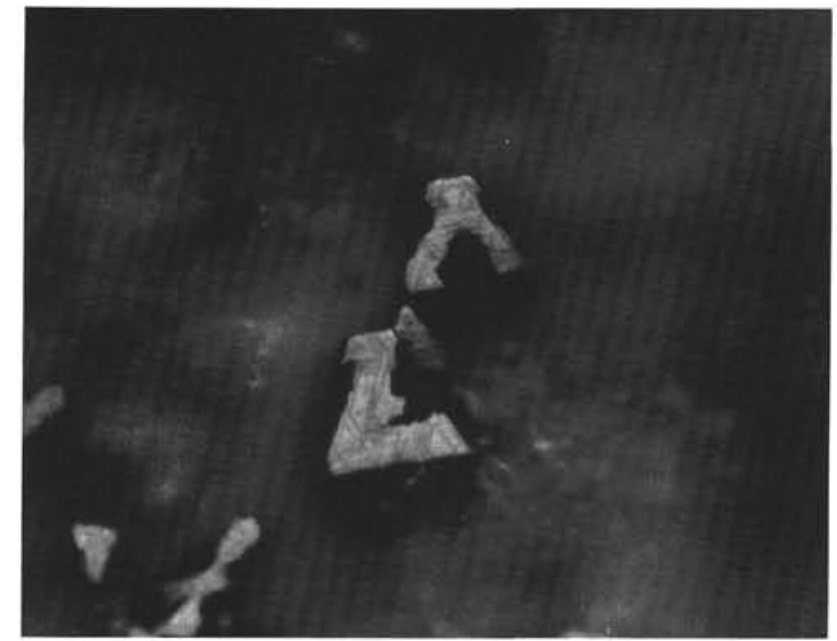

2

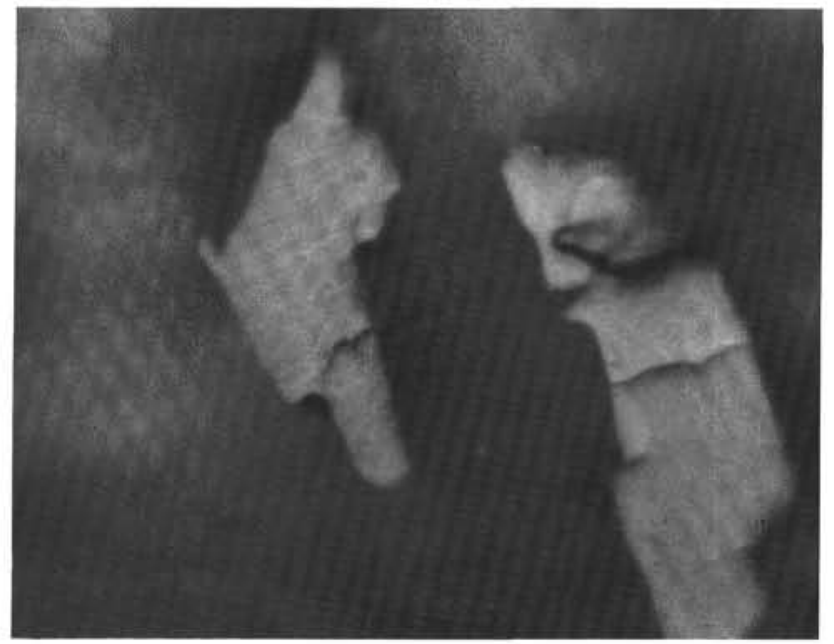

4

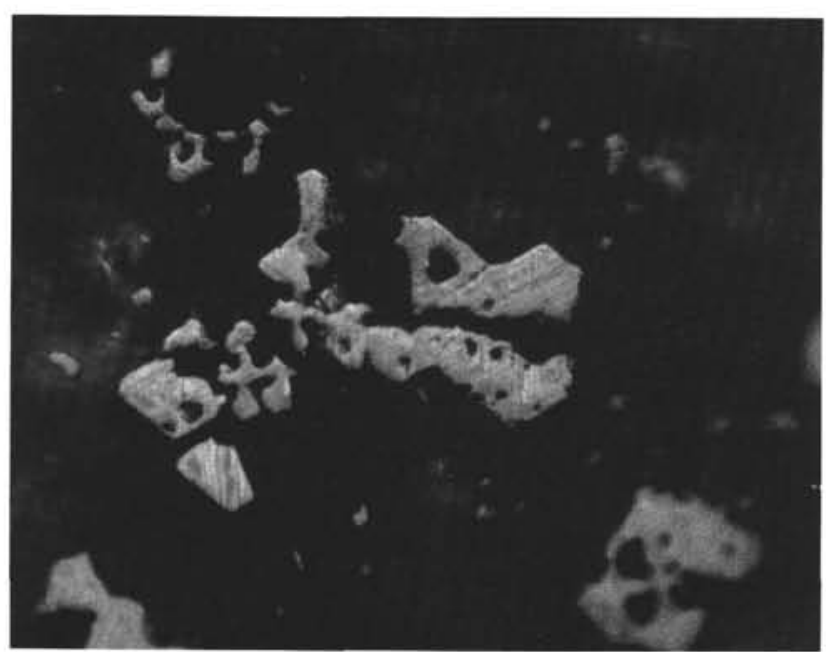

5

Plate 1. Reflected light photomicrographs of oxide grains from Leg 121 basalts. All were taken with an oil lens at $1200 \times$. The field of view is approximately 100 $\mu \mathrm{m}$. 1. Ilmenite-magnetite grain showing cracking and incipient granulation associated with low-temperature alteration. Only the titanomagnetite portion of the grain is cracked (Sample 121-756D-5R-1, 25-27 cm). 2. Trellis lamellae in a small grain (Sample 121-757C-11R-3, 115-117 cm). 3. Primary ilmenite-magnetite combination (Sample 121-757C-11R-1, 49-51 cm). See also Figure 1.4. Ilmenite grains veined with a light mineral (magnetite?) (Sample 121-756D-6R-1, 73-75 $\mathrm{cm})$. 5. Complex dendrite with exsolution lamellae (Sample 121-756D-11R-2, 49-51 cm). 